\title{
Control of germ-band retraction in Drosophila by the zinc-finger protein
} \section{HINDSIGHT}

\author{
M. L. Richard Yip ${ }^{1, \star}$, Michele L. Lamka ${ }^{1, \dagger}$ and Howard D. Lipshitz1,2,3,‡ \\ ${ }^{1}$ Division of Biology, California Institute of Technology, Pasadena, California, USA \\ 2Program in Developmental Biology, Division of Endocrinology and Department of Genetics, Research Institute, The Hospital for \\ Sick Children, Toronto, Canada \\ ${ }^{3}$ Department of Molecular and Medical Genetics, University of Toronto, Toronto, Canada
}

*Present address: ABL-Basic Research Program, NCI-Frederick Cancer Research and Development Center, Frederick, Maryland 21702, USA †Present address: Department of Biology, University of Virginia, Charlottesville, Virginia 22903, USA

‡Author for correspondence at: Research Institute, The Hospital for Sick Children, 555 University Avenue, Toronto, Ontario, Canada M5G 1X8 (e-mail: lipshitz@sickkids.on.ca)

\section{SUMMARY}

Drosophila embryos lacking hindsight gene function have a normal body plan and undergo normal germ-band extension. However, they fail to retract their germ bands. hindsight encodes a large nuclear protein of 1920 amino acids that contains fourteen $\mathrm{C}_{2} \mathrm{H}_{2}$-type zinc fingers, and glutamine-rich and proline-rich domains, suggesting that it functions as a transcription factor. Initial embryonic expression of hindsight RNA and protein occurs in the endoderm (midgut) and extraembryonic membrane (amnioserosa) prior to germ-band extension and continues in these tissues beyond the completion of germ-band retraction. Expression also occurs in the developing tracheal system, central and peripheral nervous systems, and the ureter of the Malpighian tubules. Strikingly, hindsight is not expressed in the epidermal ectoderm which is the tissue that undergoes the cell shape changes and movements during germ-band retraction. The embryonic midgut can be eliminated without affecting germ-band retraction. However, elimination of the amnioserosa results in the failure of germ-band retraction, implicating amnioserosal expression of hindsight as crucial for this process. Ubiquitous expression of hindsight in the early embryo rescues germ-band retraction without producing dominant gainof-function defects, suggesting that hindsight's role in germ-band retraction is permissive rather than instructive. Previous analyses have shown that hindsight is required for maintenance of the differentiated amnioserosa (Frank, L. C. and Rushlow, C. (1996) Development 122, 1343-1352). Two classes of models are consistent with the present data. First, hindsight's function in germ-band retraction may be limited to maintenance of the amnioserosa which then plays a physical role in the retraction process through contact with cells of the epidermal ectoderm. Second, hindsight might function both to maintain the amnioserosa and to regulate chemical signaling from the amnioserosa to the epidermal ectoderm, thus coordinating the cell shape changes and movements that drive germ-band retraction.

Key words: hindsight, zinc finger, germ-band retraction, Drosophila, morphogenesis

\section{INTRODUCTION}

In metazoa morphogenetic cell shape changes and movements are important in the formation of complex three-dimensional body structures (Bard, 1994). The genetic approach - particularly in Drosophila — is beginning to yield important insights into the mechanisms that control and coordinate these morphogenetic processes. Such genetic strategies have previously illuminated the mechanisms by which cells are assigned positional values and are fated to contribute to particular tissue types (Lewis, 1996; Nüsslein-Volhard, 1996; Wieschaus, 1996). During Drosophila embryogenesis, several coordinated morphogenetic processes occur shortly after blastoderm cellularization is completed (Campos-Ortega and Hartenstein, 1985; Costa et al., 1993; Martinez Arias, 1993). First, mesoderm is internalized through the formation of the ventral furrow. The endoderm then invaginates from each end of the embryo as the anterior and posterior midgut. Concurrent with posterior midgut invagination, germ-band extension drives cells around the posterior tip of the embryo, converting it into a ' $U$-shape' folded upon itself dorsally. Several hours later, the germ band retracts back around the posterior tip, repositioning the caudalmost body parts at the posterior end of the embryo.

The cellular events and the genetic control of several of these morphogenetic processes are now under study. For example, it has been shown that mesodermal and posterior midgut invaginations occur in two phases (Kam et al., 1991; Sweeton et al., 1991). The first is slow and stochastic, with isolated cells within the presumptive mesoderm and endoderm initiating apical constriction. The second phase is rapid with all of the unconstricted cells in these domains simultaneously undergoing apical constriction (Kam et al., 1991; Sweeton et al., 1991). Two known loci - concertina (cta) and folded gastrulation $(f \circ g)$ - are required for the transition from the first to the 
second phase (Zusman and Wieschaus, 1985; Parks and Wieschaus, 1991; Sweeton et al., 1991; Costa et al., 1994). cta encodes a $\mathrm{G}_{\alpha}$-like protein that is produced maternally and deposited in the egg and early embryo (Parks and Wieschaus, 1991). fog encodes a novel putative secreted protein that is expressed in the invagination primordia in a pattern that precisely prefigures the pattern of apical cell constrictions (Costa et al., 1994). It has been suggested that these two gene products constitute part of a signaling pathway that coordinates the group behaviour of the cells undergoing morphogenetic alterations. Neither cta nor fog mutations affect the assignment of positional values to cells; rather they specifically disrupt coordinate cell shape changes.

In contrast to the mesodermal and endodermal invaginations, germ-band extension is not driven by cell shape changes but by cell rearrangements (Irvine and Wieschaus, 1994): extensive intercalation of cells results in a decrease in cell number along the dorsoventral (D-V) axis of the embryo with a concomitant increase in cell number along the anteroposterior (A-P) axis.

Germ-band retraction is attained through a combination of cell shape changes and cell rearrangements, with the former playing a more important role than the latter (Campos-Ortega and Hartenstein, 1985; Martinez Arias, 1993). Cell shape changes in the epidermal ectoderm account for a $40 \%$ reduction along the A-P axis and an $85 \%$ increase across the $\mathrm{D}-\mathrm{V}$ axis relative to the unretracted state (Martinez Arias, 1993). Local cell rearrangements produce a further $10 \%$ decrease along the A-P axis with a concomitant $15 \%$ increase across the D-V axis (Martinez Arias, 1993). These cell shape changes and local cell rearrangements begin in the thoracic region and spread posteriorly (Martinez Arias, 1993).

Expression of six genes is required zygotically for germband retraction: the Drosophila homolog of the mammalian EGF receptor (variously called top, $f b$ and DER and referred to here as Egfr) (Clifford and Schüpbach, 1989; Raz et al., 1991), the Drosophila homolog of the mammalian insulin receptor (encoded by the inr gene) (Fernandez et al., 1995), hindsight (hnt) (Wieschaus et al., 1984; Strecker et al., 1991, 1992), tailup (tup) (Nüsslein-Volhard et al., 1984), u-shaped (ush) (Nüsslein-Volhard et al., 1984) and serpent (srp) (Jürgens et al., 1984; Reuter, 1994). Four of these genes, the Egfr (Clifford and Schüpbach, 1992), hnt, ush and srp (Frank and Rushlow, 1996) are required for the maintenance of the differentiated amnioserosa.

In this report, we present our analysis of the hnt mutant phenotype and report the molecular cloning and analysis of the expression of the $h n t$ gene. Our results indicate that $h n t$ does not affect pattern formation or tissue specification prior to germ-band retraction. The sequence of the hnt cDNA and localization of HNT protein in nuclei suggest that it functions as a zinc-fingercontaining transcriptional regulator. Strikingly, hnt is not expressed in the epidermal ectoderm that undergoes the cell shape changes and movements that drive germ-band retraction. Rather, $h n t$ is expressed in the endoderm and amnioserosa prior to, during and after retraction. Based on analysis of single and double mutants that eliminate expression of hnt in the regions that normally form midgut and/or amnioserosa, we argue that $h n t$ expression in the amnioserosa is crucial for germ-band retraction. Two models are presented: a 'physical' model in which hindsight functions to maintain the differentiated amnioserosa which then controls retraction through direct physical interaction with cells of the germ band; and a "chemical' model in which hindsight functions to maintain the amnioserosa, which then produces or activates a signal that is received by the germ band and coordinates germ-band retraction.

\section{MATERIALS AND METHODS}

\section{Drosophila genetics and culture conditions}

Flies were raised on standard medium at $25^{\circ} \mathrm{C}$ unless otherwise specified. The original $h n t$ alleles, $h n t^{X E 81}$ and $h n t^{X 001}$, were isolated by Wieschaus et al. (1984). Two additional alleles, $h n t^{E H 587}$ and $h n t^{E H 704 a}$, were obtained in a subsequent EMS mutagenesis screen (Eberl and Hilliker, 1988). We report here, that a putative fifth allele, l(1)EH275a (Eberl and Hilliker, 1988) also referred to as $h n t^{E H 275 a}$ (Ray, 1993), is in fact not allelic to hnt. Most other mutations used in this study are described in detail in Lindsley and Zimm (1992); alleles used were: cact $^{A 2}$, cact $^{H E 9}$, cta $^{W U 31}, E g f_{f}{ }^{f 1}$, fog $^{S 4}, h^{2 b^{2}}$, peb $^{1}$, pll $^{078}$, pll $^{385}$, sax $^{H B 18}$, sax ${ }^{W O 18}$, srp $^{9 L}$, tld $^{9}, t^{1} l^{1}$, tor $^{P M 51}$, tor $^{\text {splc }}$ and zen ${ }^{f 62} . t^{6 d^{68-62}}$ is described in Shimell et al. (1991). All zygotic lethal mutations were maintained over appropriate 'blue balancer' chromosomes harboring a P-element transgene that expresses $\beta$-galactosidase under the control of the $\mathrm{ftz}$ promoter: FM7Z (Kania et al., 1990), CyOZ (Raz and Shilo, 1993), TM3Z (S. Smolick-Utlaut and E. B. Lewis, personal communication). Flies carrying the temperature-sensitive rough-eyed mutation, pebbled, were raised at $28 \pm 1^{\circ} \mathrm{C}$, the restrictive temperature.

\section{Analysis of embryonic cuticles and quantitative analysis of germ-band retraction}

Embryos were collected for 24 hours and allowed to age at least an additional 24 hours. In most cases, cuticles were prepared by clearing dechorionated embryos in mounting medium as described in Ashburner (1989), except that embryos were not fixed before mounting. In cases where the vitelline membrane was removed for analysis, unhatched embryos were dechorionated with $50 \%$ bleach for 2 minutes, transferred to methanol:heptane (1:1) and vortexed to remove vitelline membranes. Embryonic cuticles were then fixed, mounted and analyzed as previously described (Lamka et al., 1992). For quantitative analysis of the germ-band retraction defects, hatched versus unhatched embryos were counted and the latter class was then processed for cuticle analysis. The extent of germ-band retraction was measured by noting which abdominal segment was located at the posterior tip of the embryo; half-segment measures were used to increase resolution (see Results; Figs 1, 2). Complete retraction positions the telson at the tip.

\section{Time-lapse videomicroscopy}

Embryos were collected for 0.5 hour intervals from balanced heterozygous hnt females. The embryos were submerged in halocarbon oil and were filmed under bright-field illumination at $21 \pm 1^{\circ} \mathrm{C}$ for more than 12 hours, usually in groups of three to four at a time. Filming was done using a Dage-MTI CCD72 videocamera attached to a Nikon Diaphot-TMD inverted microscope and recorded with a Hitachi/ GYYR time-lapse VCR.

\section{Histology and immunohistochemistry}

Antibody staining of embryos was according to established procedures (Macdonald and Struhl, 1986; Patel et al., 1989). Primary antibodies were mouse anti-ABD-B monoclonal antibody $(\mathrm{mAb})(1: 2$ dilution) (Celniker et al., 1989); rat anti-CUT (1:300) (Blochlinger et al., 1990); mouse anti-FKH (1:33) (Y. M. Kuo and S. K. Beckendorf, personal communication); rabbit anti-KR (1:200) (Gaul et al., 1987; M. Levine, personal communication); rabbit anti-LAB (1:75) (Diederich et al., 1991); $\mathrm{mAbD}_{3}$ (1:15) (68G5D3) (Giniger et al., 1993); mAb 22C10 (1:2) (Fujita et al., 1982); mouse anti- $\beta$-galac- 
tosidase (1:200 to 1:500) (Promega, Inc.); mouse monoclonal antiHNT antibody 27B8 1G9 (1:10 to 1:20) (see below). Secondary antibodies were alkaline phosphatase-conjugated goat anti-mouse, goat anti-rabbit or donkey anti-rat antisera (Jackson Immunoresearch) used at 1:500-1:2000 dilution or goat anti-mouse or goat anti-rabbit antisera conjugated to horse radish peroxidase (HRP) (Jackson Immunoresearch) used at a dilution of 1:300. Since all zygotic lethal mutations were maintained over appropriate 'blue balancer' chromosomes (above) mutant embryos were identified by simultaneously staining batches of embryos with both anti- $\beta$-galactosidase and the particular antibody of interest.

\section{Nucleic acid manipulations and analysis}

Standard protocols were as described (Sambrook et al., 1989). Overlapping phage genomic DNA clones covering about $70 \mathrm{~kb}$ proximal to the proximal deficiency breakpoint of $D f(1) r b^{46}$ (Pflugfelder et al., 1990) were hybridized to ${ }^{32} \mathrm{P}$-labeled cDNA probes synthesized from 0-3 hour embryonic poly(A) RNA. A $4.5 \mathrm{~kb}$ BamHI fragment from phage clone X-59 (which substantially overlaps clone X-32) and located at $+130 \mathrm{~kb}$ on the chromosomal walk (Pflugfelder et al., 1990) was identified as hybridizing to the cDNA and was then used to screen a cDNA library (Poole et al., 1985). We isolated a cDNA clone, designated E20, with a $2 \mathrm{~kb}$ insert and, using this as a probe, we screened a second embryonic cDNA library to isolate longer cDNA clones (Brown and Kafatos, 1988). Iterative screening using probes derived from the $5^{\prime}$-most portions of progressively longer cDNAs resulted in the isolation of long cDNA clones encompassing the entire open reading frame (e.g. NB701). Sequencing of cDNA inserts was done using the Sequenase kit (US Biochemical Corp.) or the Cycle Sequencing Kit (Applied Biosystems, Inc.).

\section{Molecular analysis of mutant alleles}

Genomic DNA was isolated from hnt mutant embryos using at least 100 embryos for each preparation. The polymerase chain reaction (PCR) was used to amplify fragments of the hnt coding region from this genomic DNA; for each amplified fragment, triplicate PCR reactions were set up and processed simultaneously. Primers were: forward 5'-GCCAGTCTCTCGGAATCGGG-3' derived from nucleotides 719-738 of the hnt cDNA sequence; reverse 5'TCGCAGGCGGGACAACTTAG-3' derived from nucleotides 18061787 of the hnt cDNA sequence. After PCR amplification, the triplicate reactions were combined and the amplifed fragment was purified using QIAquick PCR Purification Kit (Qiagen). Amplified DNA was then sequenced. The primers relevant to the point mutation in $h n t^{\mathrm{X} 001}$ were: forward 5'-TGCTATCCTCGGCTTCATCC-3' derived from nucleotides 1110-1129 of the hnt cDNA sequence; reverse 5'-CTGCGACTGTGACTATGTCCAC-3' derived from nucleotides 1473-1452 of the hnt cDNA sequence.

\section{Germ-line transformation and phenotypic rescue}

A $6.3 \mathrm{~kb}$ SspI-NotI fragment containing the entire NB701 cDNA was cloned into the HpaI-NotI sites of the $p C a S p e R-h s$ vector (Thummel and Pirrotta, 1991) and transformed into the germ line (Rubin and Spradling, 1982; Spradling and Rubin, 1982). Two transgenic lines were obtained: $h s-h n t: E$ (X chromosome) and $h s-h n t: M$ (2nd chromosome). For rescue experiments, virgin females from each of the four $y$ hnt mutant stocks were mated to males from the $h s-h n t: M$ transgenic line. The experimental crosses were: $y$ hnt/FM7Z $\times w^{1118} / Y$; $h s$ hnt:M/hs-hnt:M; control crosses were: $y$ hnt/FM7Z $\times w^{1118} / Y$. All progeny from the experimental crosses carry one copy of the $h s-h n t$ transgene and were collected on yeasted grape juice-agar plates at 2 to 2.5 hour intervals. 3.5 or 4 hours after collection, embryos were heat shocked twice at $36.5^{\circ} \mathrm{C}$ for 0.5 hour per treatment with an interval of 0.5 hour at $25^{\circ} \mathrm{C}$ between heat shocks. Embryos were then allowed to develop at $25^{\circ} \mathrm{C}$ before cuticles were mounted for analysis. hnt mutant embryos were identified on the basis of the $y$ marker.

\section{Whole-mount RNA tissue in situ hybridization}

Whole-mount RNA tissue in situ hybridization was based on previously published protocols (Tautz and Pfeifle, 1989; Ding et al., 1993). Digoxigenin (DIG)-labeled hnt DNA probe was synthesized from a 2 $\mathrm{kb}$ EcoRI fragment containing the $3^{\prime}$ end of hnt. DIG-labeled hnt antisense RNA probe was synthesized by in vitro transcription off the T7 promoter using cDNA NB701 as template. Both DNA and RNA probes gave identical results.

\section{Expression of HNT fusion protein and production of anti- HNT antibodies}

A 907 bp BglII-BamHI fragment from cDNA NB701 (nucleotides 2710 to 3617 ; codons 824 to 1125 ) encoding a 302 amino acid HNT polypeptide was cloned into the BamHI site of pGEX1 (Smith and Johnson, 1988). The GST-HNT fusion protein was expressed and purified from E. coli (Ausubel et al., 1987). To generate anti-HNT antibodies, $50 \mu \mathrm{g}$ of purified GST-HNT fusion protein suspended in RIBI adjuvant (RIBI Biochem) was injected into three Balb/c mice (Simenson). Antisera from the mice were tested by ELISA against the fusion protein and on fixed Drosophila embryos. The blood from the mouse that produced the strongest response was saved as anti-HNT polyclonal antiserum. This mouse was then killed for monoclonal antibody production that followed standard procedures (Harlow and Lane, 1988) and used HL-1 myeloma cells (Hycor). Monoclonal supernatants were tested on fixed embryos. The monoclonal anti-HNT antibody used in most of our experiments is designated 27B8 1G9 and was used at a 1:10 to 1:20 dilution of supernatant.

\section{RESULTS}

\section{hindsight function is required for the morphogenetic movements that drive germ-band retraction}

Four embryonic lethal alleles of the X-linked gene hindsight (hnt) have been reported (Wieschaus et al., 1984; Eberl and Hilliker, 1988; Lindsley and Zimm, 1992). A fifth potential allele, l(1)EH275a (Eberl and Hilliker, 1988), is not allelic to hnt (see below). We demonstrate here and in a separate study that pebbled (peb) mutations are viable alleles of hnt (M. L. R. Y., Q. Sun, M. L. L. and H.D. L., unpublished data). The four embryonic lethal alleles $h n t^{X E 81}, h n t^{X 001}, h n t^{E H 704 a}$ and $h n t^{E H 587}$ display qualitatively similar phenotypes: hemizygous $(h n t / Y)$ embryos fail to retract their germ bands (Figs 1, 2). All such embryos have the correct number of thoracic and abdominal segments which are patterned normally. As a consequence of failed germ-band retraction, the embryos are Ushaped with their posterior region folded onto the dorsal side (Fig. 1B-D). Additionally, mutant embryos show defects in head involution and often have a severely disrupted cephalopharyngeal skeleton (Fig. 1B-D) (Ray, 1993; Yip, 1995; Frank and Rushlow, 1996).

l(1)EH275a (Eberl and Hilliker, 1988) has previously been classified as a semi-lethal $h n t$ allele and referred to as $h n t^{275 a}$ (Ray, 1993). Germ-band retraction occurs in most l(1)EH275a embryos, but these usually die with head defects and occasional dorsal holes. Normal looking l(1)EH275a escaper adult males can emerge but they are often sterile, sometimes exhibiting partially unrotated external genitalia. Thus it has not previously been possible to determine whether $l(1) E H 275 a$ is indeed allelic to hnt (Eberl and Hilliker, 1988). We have recently used an autosomal duplication of the wild-type hnt locus to carry out inter se complementation tests among all putative $h n t$ alleles (B. Reed and H. D. L., unpublished obser- 

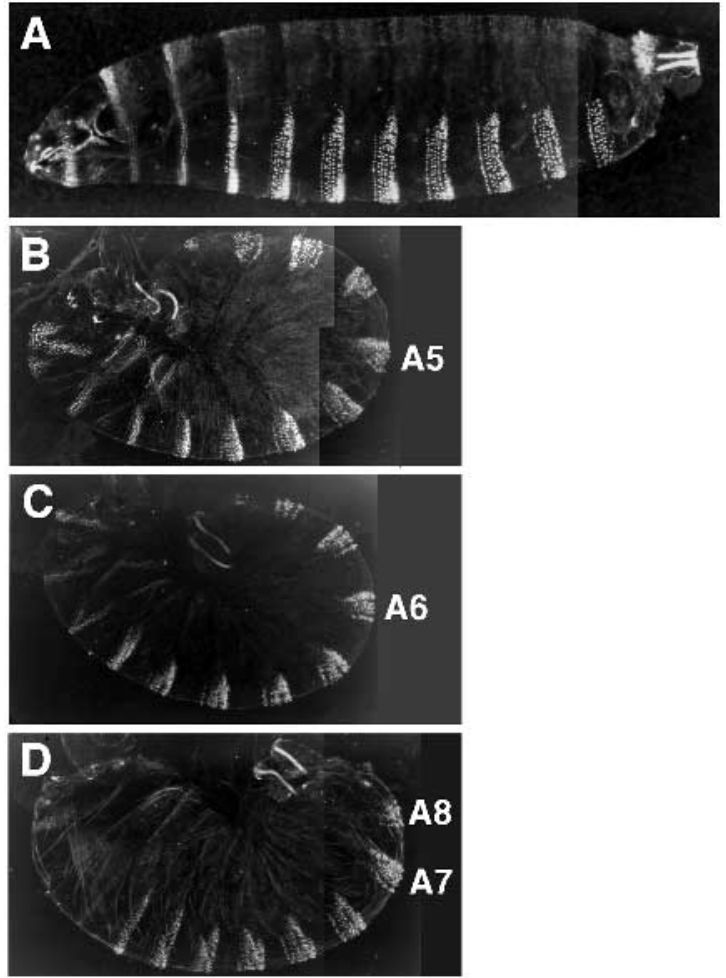

Fig. 1. hindsight mutant cuticular phenotypes. (A) Wild-type stage 17 embryonic cuticle; (B-D) cuticles of stage 17 hemizygous hnt ${ }^{\text {XOO1 }}$ mutant embryos. (B) The 'strong' unretracted germ-band phenotype. Cuticle of a hemizygous $h n t^{X 001}$ mutant embryo with abdominal segment 5 (A5) at the posterior pole. Note the normal thoracic and abdominal segments and the abnormal head skeleton. (C) An 'intermediate' germ-band retraction phenotype with A6 at the posterior pole. (D) A 'weak' germ-band retraction phenotype with A7.5 at the posterior pole. Embryos are oriented with anterior to the left and dorsal toward the top of the page.

vations). l(1)EH275a complements embryonic lethal $h n t$ alleles $\left(h n t^{X E 81}, h n t^{X 001}\right.$, $h n t^{E H 704 a}$ ) (B. Reed and H. D. L., unpublished observations). l(1)EH275a also complements a chromosomal deletion, Df(1)ovoG6 (Pflugfelder et al., 1990), that removes most of the hnt locus (B. Reed and H. D. L., unpublished observations). In addition, $l(1) E H 275 a$ complements the viable $h n t$ allele, $h t^{p e b}$ (M. L. R. Y. and H. D. L., data not shown; see below). We thus conclude that l(1)EH275a is not allelic to $h n t$.

We have identified an additional, viable $h n t$ allele that was originally named pebbled (peb) because of its rough eye phenotype (Lindsley and Zimm, 1992). None of the four embryonic lethal alleles complements the pebbled rough eye phenotype (Table 1), suggesting that hindsight and pebbled are allelic. Detailed analyses of $h n t$ functions during eye development will be reported separately (M. L. R. Y., Q. Sun, M. L. L. and H.D. L., unpublished data). We shall refer to $p e b$ henceforth as $h n t^{p e b}$. Table 1 presents a summary of $h n t$ mutant phenotypes.

While previous studies have carried out a survey of cuticular and/or amnioserosal defects, to date there has been no quantitative analysis of germ-band retraction in hnt mutant embryos (Eberl and Hilliker, 1988; Ray, 1993; Frank and Rushlow, 1996). We quantified germ-band retraction by examining populations
Table 1. hindsight mutant phenotypes

\begin{tabular}{lccc}
\hline Alleles & $\begin{array}{c}\text { Embryonic } \\
\text { lethality }\end{array}$ & $\begin{array}{c}\text { Germ-band } \\
\text { retraction }\end{array}$ & $\begin{array}{c}\text { Complementation } \\
\text { of pebbled rough } \\
\text { eye phenotype }\end{array}$ \\
\hline$h n t^{X E 81}$ & lethal & --- & no \\
$h n t^{E H 587}$ & lethal & -- & no \\
$h n t^{E H 704 a}$ & lethal & -- & no \\
$h n t^{X 001}$ & lethal & - & no \\
$h n t^{p e b}$ & viable & + & no \\
,--- strong failure of retraction (mode of retraction distribution at \\
abdominal segment 5.0, see Fig. 2). \\
,-- intermediate failure of retraction (mode at 6.0, see Fig. 2). \\
- , weak failure of retraction (mode at 7.0, see Fig. 2). \\
$\quad+$, retraction complete. \\
\hline \multicolumn{4}{l}{}
\end{tabular}

of mutant embryos and plotting the distribution of abdominal segments lying at the posterior tip (Fig. 2; see Materials and Methods). The embryonic-lethal hnt alleles represent a phenotypic series with respect to failure of germ-band retraction (Figs $1,2)$. When hemizygous, a deletion of the hnt locus, $D f(1) b i^{D 3}$ (Banga et al., 1986; Oliver et al., 1988), results in 100\% of the embryos with abdominal segment 4.5 to 6.0 at the posterior tip (Fig. 2A). The strongest $h n t$ allele studied, $h n t^{X E 81}$, is similar to the deletion in that the mode of the distribution lies at abdominal segment 5.0. However, this distribution is broader than that produced by the deletion; $12 \%$ of the embryos have abdominal segment 6.5 or greater at the posterior tip (Fig. 2B), a situation not seen with $D f(1) b i^{D 3}$. Weaker still are $h n t^{E H 704 a}$ and $h n t^{X 001}$; respectively, $36 \%$ and $68 \%$ of the embryos have segment 6.5 or greater at the posterior tip (Fig. 2C,D). $h n t^{E H 587}$ is very similar in distribution to $h n t^{E H 704 a}$ (data not shown).

\section{hindsight mutants do not exhibit defects in pattern or tissue specification prior to germ-band retraction}

We wished to determine whether the morphogenetic process of germ-band retraction failed in hnt mutants without significant defects in tissue specification or pattern formation. With the exception of the head, the cuticle of hnt mutant embryos does not show any pattern defects (Fig. 1) (Yip, 1995). In order to study the internal tissues, we examined embryos carrying the strongest mutant allele $h n t^{X E 81}$ with a panel of antibodies that recognize proteins/epitopes with different temporal and spatial expression patterns and functions (Table 2). With one exception, all of these markers exhibited no obvious differences between $h n t^{X E 81}$ mutant embryos and wild-type embryos prior to germ-band retraction. The exception, KRÜPPEL, which accumulates in wild-type embryos in the nuclei of amnioserosal cells, is absent from most but not all of these cells in stage 11 hnt mutant embryos (Fig. 3) (Ray, 1993).

\section{hindsight mutants undergo normal germ-band extension}

Our examination of the external and internal tissues of $h n t$ mutants revealed neither pattern abnormalities nor defects in tissue specification prior to germ-band retraction. However, it remained possible that, while cell position and tissue specification were normal, earlier morphogenetic events were abnormal and thus that failure of germ-band retraction was a secondary consequence of such defects. For example, if $h n t$ mutants were 
defective in the timing or the spatial aspects of germ-band extension, germ-band retraction might fail as a consequence of inappropriate positioning of tissues to receive a 'retraction signal'. In order to avoid the ambiguities inherent in analyses
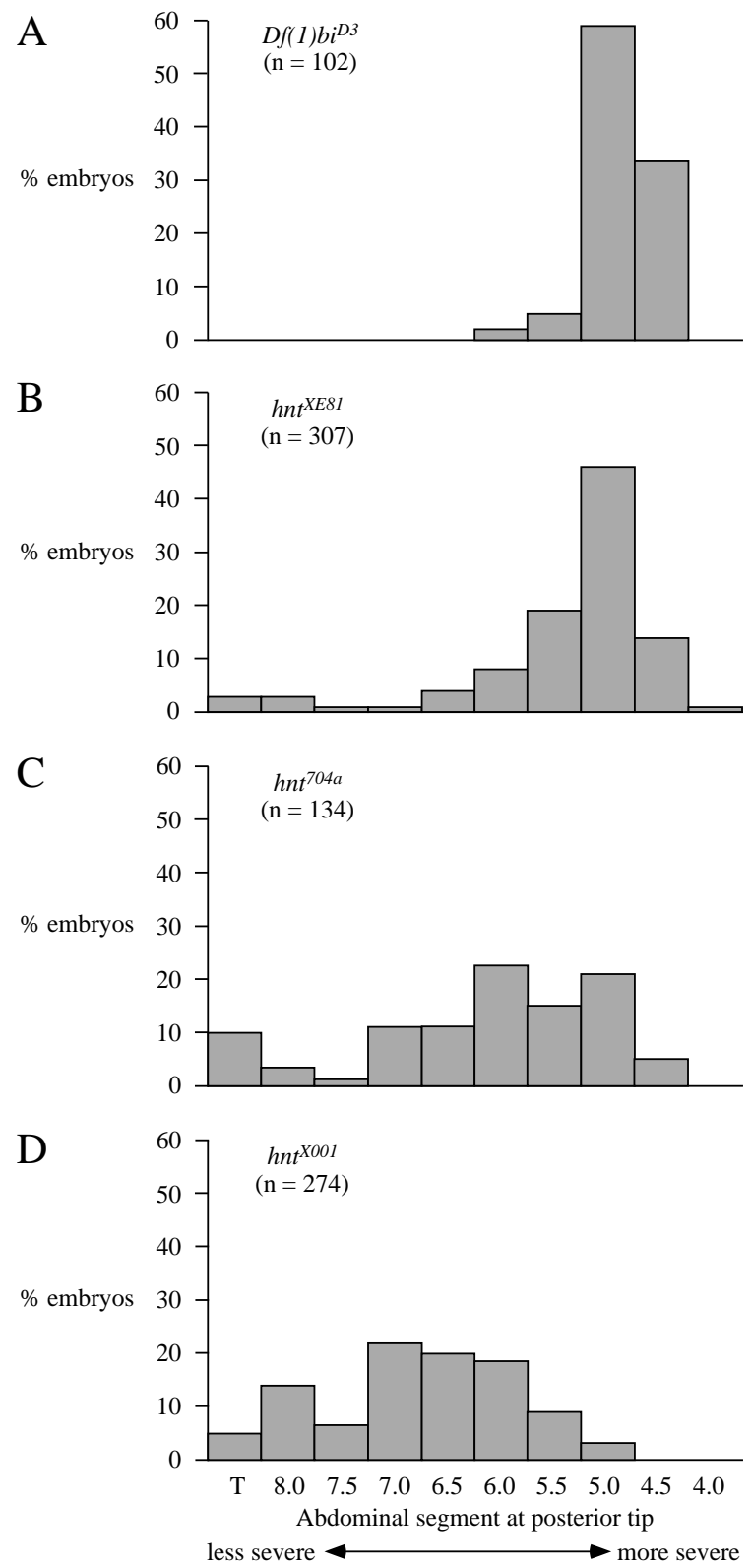

Fig. 2. Quantitative analysis of germ-band retraction in embryonic lethal hindsight mutants. Populations of unhatched embryos ( $n$, number of unhatched embryos) were scored for the abdominal segment at the posterior tip (abscissa) (see Materials and Methods and Results for details). The percentage (\%) of the unhatched embryos with a particular abdominal segment at the posterior is given on the ordinate. (A) $D f(1) b i^{D 3}$. Deletion of the $h n t$ gene results in $98 \%$ of the embryos with abdominal segment $5.0 \pm 0.5$ at the posterior tip. (B) $h n t^{X E 81}$. This strongest allele of $h n t$ results in $79 \%$ of the embryos with abdominal segment $5.0 \pm 0.5$ at the posterior tip. (C) $h n t^{704 a}$. This intermediate $h n t$ allele results in only $41 \%$ of the embryos with abdominal segment $5.0 \pm 0.5$ at the posterior tip. (D) $h n t^{X 001}$. This weak $h n t$ allele results in only $12 \%$ of the embryos with abdominal segment 5.0 \pm 0.5 at the posterior tip. of fixed material, we used time-lapse video microscopy of living $h n t^{E H 704 a / Y}$ mutant embryos to determine whether any morphogenetic defects were visible in the mutants at these earlier stages. Videotaped hnt mutant embryos were identified on the basis of their failure to retract their germ bands by 13 hour postfertilization and these embryos were then studied retrospectively for earlier morphogenetic events. $+/+$, hnt $/+,+/ Y$ and $h n t / Y$ mutant embryos extend their germ bands at indistinguishable rates and with similar spatial relationships. The first difference appears after germ-band extension is complete: three quarters of the embryos (presumably $h n t /+,+/+$ or $+/ Y$ ) initiate germ-band retraction normally while the remaining quarter of them (presumably $h n t / Y$ ) either did not initiate retraction or initiated premature retraction-like movements (4 hours after the beginning of germ-band extension in $h n t / Y$ versus 7.5 hours in $h n t /+,+/+$ or $+/ Y$ siblings at $21 \pm 1^{\circ} \mathrm{C}$ ) but failed to complete the process. The proportion of the embryos that underwent retraction-like movements correlated with the strength of the $h n t^{E H 704 a}$ allele determined on the basis of cuticle analysis: 7/11 videotaped mutant embryos $(57 \%)$ underwent some retractionlike movements, consistent with the fact that $59 \%$ of the $h n t^{E H 704 a}$ cuticles exhibited abdominal segment 6.0 or greater at the posterior tip (Fig. 2C). We conclude that the hnt gene is not required for early embryonic pattern specification, tissue specification or earlier morphogenetic events, such as germband extension.

\section{The hindsight gene encodes a putative zinc-finger transcription factor}

Previous studies mapped hnt within polytene chromosome region 4C5/6 (Oliver et al., 1988; Lindsley and Zimm, 1992). In contrast to published data (Oliver et al., 1988), we found that the deficiency chromosome, $D f(1) r b^{46}$, complements the rough eye phenotype of $h n t^{p e b}$, placing $h n t$ proximal to the proximal breakpoint of $D f(1) r b^{46}$. A chromosomal walk that spanned the proximal breakpoint of $D f(1) r b^{46}$ had been conducted in this region (Pflugfelder et al., 1990). Using over-

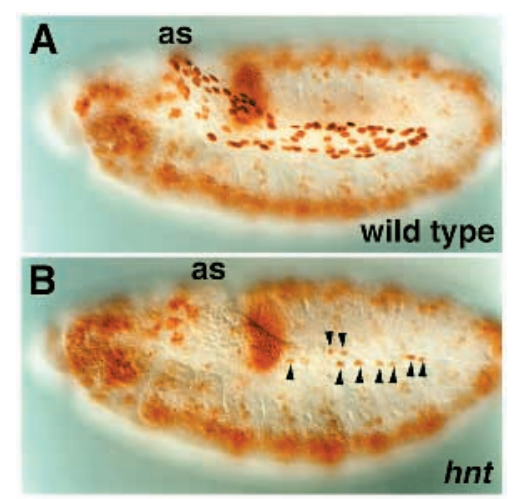

Fig. 3. KRÜPPEL expression is lost from most cells of the amnioserosa (as) of hnt embryos. (A) Germ-band-extended Oregon$\mathrm{R}$ (wild-type) stage 11 embryo stained for KRÜPPEL protein. Note the presence of KRÜPPEL in the amnioserosa. (B) Germ-bandextended $h n t^{X E 81} / \mathrm{Y}$ mutant stage 11 embryo stained for KRÜPPEL protein. Note the absence of KRÜPPEL from most but not all cells of the amnioserosa (arrowheads point to amnioserosal nuclei that contain KRÜPPEL). Other aspects of KRÜPPEL expression are normal. Embryos are oriented with anterior to the left and dorsal toward the top of the page. 
Table 2. Molecular markers used to examine hnt mutant embryos

\begin{tabular}{lll}
\hline Molecular marker & \multicolumn{1}{c}{ Relevant tissue marked } & Expression in hnt mutant embryos \\
\hline$\alpha$-Abdominal B & Hindgut, posterior spiracles & Normal \\
$\alpha$-cut & Malphigian tubules, peripheral nervous system & Normal \\
$\alpha$-forkhead & Invaginating foregut, midgut, hindgut, salivary glands & Normal \\
$\alpha$-Krüppel & Amnioserosa, central nervous system, muscle precursor cells & Loss of most amnioserosal expression; \\
& & otherwise normal \\
$\alpha$-labial & Endodermal cells around second midgut constriction & Normal \\
$m A b$ D3 & Developing tracheal system & Normal \\
$m A b 22 \mathrm{C} 10$ & All neuronal cells & Normal \\
\hline
\end{tabular}

lapping phage clones proximal to the breakpoint (kindly provided by Dr G. Pflugfelder), we initiated a search for early embryonic transcripts encoded by the region. One BamHI fragment at $+130 \mathrm{~kb}$ on their walk was identified and used to screen two embryonic cDNA libraries (see Materials and Methods). Two cDNAs, denoted E20 (the first to be identified) and NB701 (one of the longest) were analyzed in detail.

Sequence analysis of NB701 and E20 revealed that E20 was a partial cDNA and that both clones were otherwise identical in sequence. NB701 contained a single large open reading frame (ORF) of 1920 codons with $241 \mathrm{bp}$ of 5'- and $163 \mathrm{bp}$ of 3'untranslated regions. Conceptual translation of the ORF is shown in Fig. 4A. It encodes a protein with several characteristics of transcription factors [analyses were conducted using the BLAST algorithm (Altschul et al., 1990)]: $14 \mathrm{C}_{2} \mathrm{H}_{2}$ type zinc fingers (Fig. 4B) in widely spaced clusters, multiple glutaminerich domains, proline-rich domains, serine/theronine-rich domains and acidic/charged domains (Fig. 4C).

We confirmed that this cDNA is encoded by the hnt gene in three ways. First, we made an $h s p 70$ promoter- $h n t$ cDNA transgene using the NB701 clone and produced transgenic flies using P-element-mediated transformation (Rubin and Spradling, 1982; Spradling and Rubin, 1982). This transgene rescues germ-band retraction in embryos mutant for any of the four embryonic lethal alleles (Table 3). On average, $50 \%$ of the heat-shocked genotypically y hnt embryos carrying one copy of the transgene fully retracted their germ bands (' $\mathrm{T}$ ' at posterior tip). In contrast, $<5 \%$ of control $h n t^{X E 81}$ and $h n t^{X 001}$ embryos complete germ-band retraction (Table 3 cf. Fig. 2). The heat-shock regimen used did not rescue the hnt mutant head defects, nor did it induce any dominant pattern or morphogenetic defects. Second, we identified the molecular lesion

Table 3. Rescue of germ-band retraction in hindsight mutant embryos using a hs-hnt transgene

\begin{tabular}{|c|c|c|c|}
\hline $\begin{array}{l}\text { Embryonic } \\
\text { genotype }\end{array}$ & $\begin{array}{l}\text { Age at first } \\
\text { heat shock }\end{array}$ & $\begin{array}{l}\text { Age at second } \\
\text { heat shock }\end{array}$ & $\begin{array}{c}\% \text { of mutant } \\
\text { embryos } \\
\text { rescued }(n)\end{array}$ \\
\hline$y h n t^{X E 81} / Y$ & 4-6 hours & 5-7 hours & $<5(43)$ \\
\hline y hnt $\mathrm{t}^{\mathrm{X001}} / \mathrm{Y}$ & 4-6 hours & 5-7 hours & $<5(21)$ \\
\hline$y h n t^{X E 81} / \mathrm{Y} ;$ hs-hnt:M & 4-6 hours & 5-7 hours & $44(70)$ \\
\hline$y$ hnt ${ }^{X E 81} / \mathrm{Y} ;$ hs-hnt:M & 3.5-6 hours & 4.5-7 hours & $46(82)$ \\
\hline y hnt ${ }^{X 001} / \mathrm{Y} ; h s-h n t: M$ & 4-6 hours & 5-7 hours & $63(27)$ \\
\hline y hnt ${ }^{X 001} / \mathrm{Y} ;$ hs-hnt:M & 3.5-6 hours & 4.5-7 hours & $52(62)$ \\
\hline$y$ hnt ${ }^{E H 587 / Y ; ~ h s-h n t: M}$ & 4-6 hours & 5-7 hours & $51(83)$ \\
\hline$y h n t^{E H 587 / Y ; ~ h s-h n t: M}$ & 3.5-6 hours & 4.5-7 hours & $73(56)$ \\
\hline$y h n t^{E H 704 a / Y}$; $h s-h n t: M$ & 4-6 hours & 5-7 hours & $65(46)$ \\
\hline y hnt ${ }^{E H 704 a / Y}$; $h s-h n t: M$ & 3.5-6 hours & 4.5-7 hours & $84(67)$ \\
\hline
\end{tabular}

caused by the EMS-induced allele $h n t^{X 001}$. Sequence analysis of fragments PCR-amplified from $h n t^{X 001}$ genomic DNA revealed a $\mathrm{C}$ to $\mathrm{T}$ transition that introduced a premature stop codon at amino acid residue 348 in place of a glutamine (CAG to TAG) (Fig. 4A,C). The truncated protein is predicted to contain only 3 of the 14 zinc fingers. Third, none of the four lethal hnt alleles shows detectable immunostaining when examined with our anti-HNT antibodies (data not shown). We conclude that we have cloned the hnt gene and that it encodes a putative zinc-finger transcription factor.

\section{hindsight is not expressed in the epidermal ectodermal cells that undergo shape change and movement during germ-band retraction, but is expressed in the amnioserosa and midgut}

The embryonic expression of hnt was determined using wholemount tissue in situ hybridization to visualize hnt RNA (data not shown) and anti-HNT antibodies to visualize HNT protein (Fig. 5). HNT protein is localized to nuclei as expected of a transcription factor. No $h n t$ mRNA or protein is detectable before stage 5 of embryogenesis, consistent with the fact that analysis of embryos produced by homozygous clones of $h n t$ cells in the germ line revealed no requirement for hnt expression or function during oogenesis (Wieschaus and Noell, 1986). hnt mRNA accumulation begins in the cellular blastoderm (stage 5) in a posteriorterminal domain corresponding to the posterior midgut primordium and dorsally in the presumptive amnioserosa (stages are according to Campos-Ortega and Hartenstein, 1985). HNT protein appears in these cells slightly later, at stage 6 (Fig. 5A). During stage 7 , dorsal expression expands to cover the entire presumptive amnioserosa from the cephalic furrow to the posterior midgut primordium (Fig. 5B). Anteroventral staining, corresponding to the anterior midgut primordium, is first detected at stage 8 (Fig. 5C). Accumulation in these tissues continues as gastrulation proceeds (Fig. 5D). Commencing at stage 11, accumulation is also detectable in the cells of the emerging larval peripheral nervous system and the tracheal system (Fig. 5E-G). Expression also occurs in peripheral and CNS glial cells (M. L. L. and H. D. L., unpublished data). The complex expression pattern of hnt suggests that it may have multiple functions during embryogenesis. Functions during the development of the embryonic nervous system (M. L. L. and H. D. L., unpublished data) and during adult eye development (M. L. R. Y., Q. Sun, M. L. L. and H. D. L., unpublished data) will be reported elsewhere. Here we focus on hnt functions in germ-band retraction since the first detectable morphogenetic defect in hnt mutants is failure of this process. Strikingly, hnt is absent from the epidermal ectodermal cells that undergo the cell shape changes and movements that drive germ-band retraction (Martinez Arias, 1993). Since hnt 
MLAAQQOHNNSTVVLEMERQRRDSTTSESSLEHLDLGRTPKKLGGNSGSTQTTSTPHELA TVTSSRKRKIRHLQLNHHQQQQHHQQSDLLSDEDVVEAEAEEDEDDEDGDQVAALGSRNL GRHKQRRSGGATTQAS IVMDYSSGDASSLRKKF RLNRSAASLSESGFVDASSTTGHSGYI GNSSSATNTTATSGIGASAVAPSPVGGAAINAASSSSGSSSGGSGGSSPQGQCLSSGESG

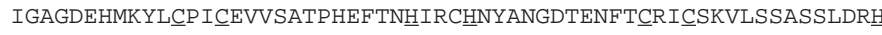
VLVHTTGERPFNCRYCCHLTFTTNGNMHRHMRT HKQHQVAQSQSQSQQQQSLQQQQQSQQQR RQQQQHQP SQQQQNPAQQQLMGNTLSAGAESYESDASCS TDVSSGHSHSRSSSS LNNNNN NSHKANNNLKDLEELEVSTEDQDTENKQRRLKT T INNNI IESEQQEDMDDEEADDADVAM

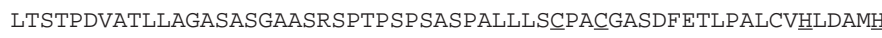
SDIPAKCRDCEVIFATHRQLQS DLEQKERLASQSEDFF HQLYLKHKTANGCGAISHPP SP I KHEPAD TKDLAD IQS I LNMTS SSSSF LRNFEQSVNTPNSSQYSLDGRDQEEEAQDAFT TEFRRMKLRGEFPCLKLCCTAVFPN

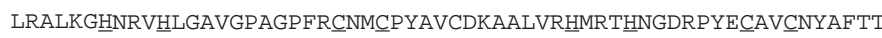
KANCERHLLRR PVNESKSQLKHMLLGENHLAPVNQQPP LKIQVKSLDQLVDKKP SAPAP QQQQQQQQQEKS GSALDF SMDVLDLSKKPTGGASLTPAVTRTP TPAAVAPVTPGGVGTPDLAAAIEQQQLLI AQQQLFGAGGEYMQQLFRSLMFQSQTSGFPFFPFMAPPPPQANPEKPPMVSPPNRINPMP VGVGVGVPVPPGGPVKMVIKNGVLMP KQKQRRYRTERPFACEHCESARFTLRSNMERHVKQ QHP QFYAQRERSAHHVMRGRGASNVAAAAAAAAAAAAP TVMAGGP GS S GF GSNHHHGHGH GSHGHAP ISEQVKCA I LAQQLKAHKNTDLLQQALAHGSS SVAGNP LLHFGYP LTNP SPMH NGSSQGNGQATAMDDDEPKLI IDEDENEHDHEVEAEDVDDFEEDEDEEEMDEPEDEPELI LDEQPAEKEAEEEQELPKPLEQLGTKEAAQKMAET I LEQAIKAGKPLSPPPTKENASPAN PTVATTMQEPAITAPSTNPSSLKTMIAQAEYVGKSLKEVASSPFKDESQDLVPVAKLVDN ATSQNMGFNSYFRP SDVANHMEQSDEEGLVASGSASESNNSGTEDVTSSSSSSEPKKKSA

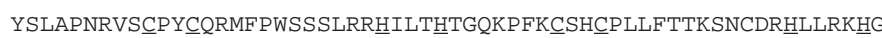
NVESAMSVYVPTEDVSEP IPVPKSVEE IELEEQRRRQEAEREKELELERERELERERELE RERQLEKEKERERQQLIQKLAAQMNAAATAAAVVAAASAVNGGASGGP HGP IADALAGGD

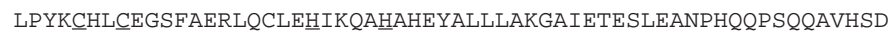
DEAPNGGGNRGKYPDYSNRKVI $\underline{C A F} \underline{C} L R R F W S T E D L R R \underline{H} M R T \underline{H} S G E R P F Q \underline{C} D I \underline{C} L R K F T I$ KHSMLRㅂMKKㅂSSGRAHNGDTPGSDCSDDEQVSSPP STPHPTQP TSANNNNSCHNNNNNAN NNNNNNNNNNNNSSSKLGLKLHDLLDKASEWRASRLGEHKENMGEATP SGATVAGSDLIG NLLGISDQGILNKLLSSRTRRPNFWVWTTSERNSSDNRATPRAINTGVAAVLHRLTYTKA
RNA and HNT protein accumulate in the endoderm and amnioserosa prior to germ-band retraction, it seemed likely that hnt expression in one or both of these tissues plays a role in the control of this morphogenetic process (see below).

\section{hindsight expression is regulated by the terminal and dorsal-ventral patterning pathways}

We carried out a survey of the genetic control of $h n t$ expression in order to enable us to begin to dissect which aspects of hnt expression are important for germ-band retraction. hnt expression in the midgut is controlled by the maternal and zygotic members of the torso-mediated 'terminal' pathway as suggested by our previous genetic studies (Strecker et al., 1989, 1991, 1992; Strecker and Lipshitz, 1990). Embryos produced by homozygous torso loss-of-function mutant females lack HNT expression in the posterior midgut which lies within the domain of tor function. Instead of extending their germ bands dorsoanteriorly, most such embryos form spiralled germ bands (Fig. 6A) (Schüpbach and Wieschaus, 1986, 1989). Reciprocally, embryos from homozygous torso ${ }^{\text {splc }}$ gain-of-function mothers lack dorsal expression (i.e. in the presumptive amnioserosa) consistent with conversion of central cell fates to more terminal ones (Schüpbach and Wieschaus, 1989; Strecker et al., 1989, 1991, 1992; Strecker and Lipshitz, 1990). These embryos also show expanded expression of HNT in the enlarged posterior midgut primordium and twisted gastrulation (Fig. 6B) (Yip and Lipshitz, 1996). Two genes, tailless $(t l l)$ and huckebein $(h k b)$, have been identified as key zygotically expressed components of the torso-mediated terminal pathway (Klingler et al., 1988; Strecker et al., 1989; Weigel et al., 1990). tll

Fig. 4. Sequence of HINDSIGHT. (A) Predicted amino acid sequence of the HNT protein based on CDNA sequence analysis (nucleotide sequence not shown but entered in the GenBank database: accession number U86010). The cysteine and histidine residues in the zinc fingers are underlined and the residue mutated from a glutamine to a stop codon (\#348) in $h n t^{X 001}$ is in bold. (B) Alignment of the 14 zinc fingers. (C) Schematic representation of the HNT protein sequence indicating the zinc fingers and domains rich in glutamine, proline, serine/threonine, acidic or charged residues.
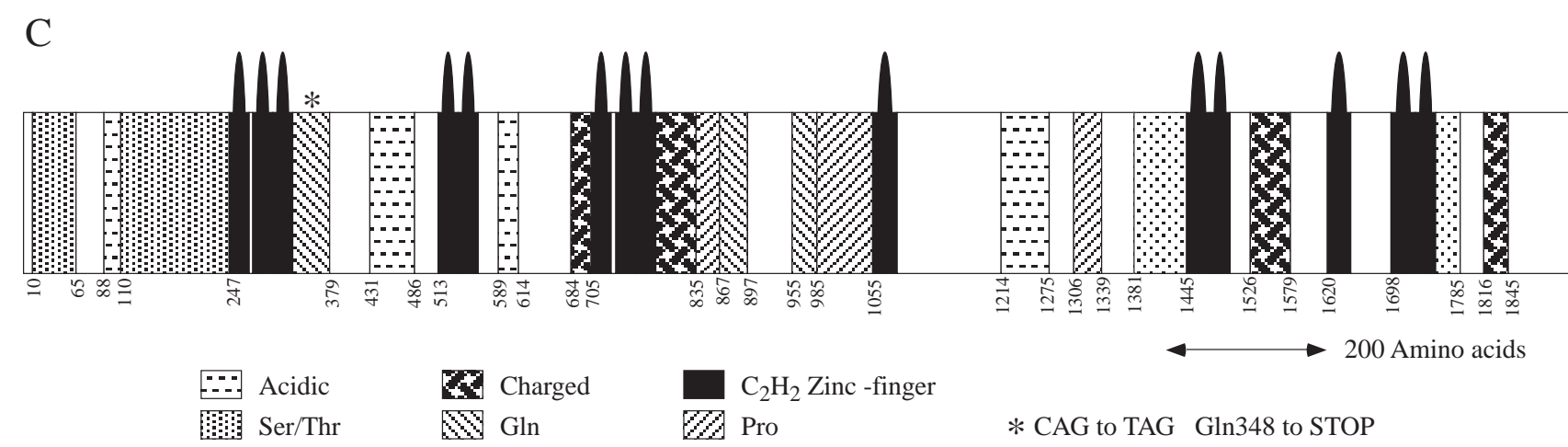

$\mathrm{C}_{2} \mathrm{H}_{2}$ Zinc -finger
2 Pro

* CAG to TAG Gln348 to STOP 
mutant embryos have an abnormal acron anteriorly, and lack abdominal segments 8-10, hindgut and Malpighian tubules posteriorly (Strecker et al., 1986, 1988; Pignoni et al., 1990). $h k b$ is required for the formation of endodermal midgut and stomodeum (Weigel et al., 1990; Brönner et al., 1994). tll mutations have little effect on HNT expression (Fig. 6C); from analysis of $h k b$ tll double mutant embryos (Fig. 6E), it is clear that the only loss of HNT expression in tll mutants occurs in the region from which the Malpighian tubule primordia originate, consistent with the reported role for $t l l$ and $h n t$ in the development of these structures (Strecker et al., 1986, 1988; Harbecke and Lengyel, 1995). $h k b$ mutant embryos lack HNT expression in the regions from which the anterior and posterior midgut normally arise; expression remains only in the presumptive ureter of the Malpighian tubules (Fig. 6D). In $h k b$ tll double mutant embryos, HNT is not expressed at all in the domains that would form anterior and posterior midgut and Malpighian tubule primordia; expression does, however, occur in the amnioserosa (Fig. 6E). Germ-band retraction occurs in tll or $h k b$ single mutants (see Fig. 7B) as well as in $h k b$ tll double mutants, suggesting that midgut expression of HNT is not necessary for germ-band retraction.

HNT expression was assayed in four mutants that are defective in germ-band retraction: serpent (srp), $u$-shaped (ush), tailup (tup) and the EGF receptor (Egfr) (Nüsslein-Volhard et al., 1984; Clifford and Schüpbach, 1989). HNT expression is not affected in ush, tup and Egfr mutants (Fig. 6G shows an Egfr mutant; data not shown for ush and tup). These results suggest that hnt either resides upstream of these three genes in the same hierarchy or one or more of these genes functions in a parallel pathway involved in germ-band retraction. In contrast, endodermal expression of HNT is missing in $s r p$ mutant embryos (Fig. 6F). This last result is consistent with the fact that $s r p$ is required to establish the identity of the endodermal midgut; loss-of-function mutations in $s r p$ result in transformation of the endoderm into ectoderm (Reuter, 1994).

HNT expression in the amnioserosa is regulated by the dorsoventral pathway. Dorsal HNT expression is reduced in genetically ventralized embryos such as those produced by saxophone (sax) or cactus (cact) females (Fig. 6H shows an embryo from a cact female; data not shown for sax) or homozyous for zen or tolloid (tld) (Fig. 7C for $t l d$; data not shown for zen). Reciprocally, dorsal HNT expression expands ventrally in dorsalized embryos (Fig. 6I shows an embryo from a pelle ( $p l l$ ) female). Anterior midgut expression of HNT is affected by the dorsoventral pathway (e.g. Fig. 6I) since anterior midgut development requires inputs from both terminal and dorsoventral pathways (Reuter and Leptin, 1994; Yip and Lipshitz, 1996). Since dorsoventral mutants fail to undergo germ-band extension, the role of amnioserosal expression of HNT in germ-band retraction could not be assayed in embryos singly mutant for any these genes (but see below).
The concertina (cta) and folded gastrulation (fog) genes are required for proper ventral furrow formation and posterior midgut invagination (Zusman and Wieschaus, 1985; Parks and Wieschaus, 1991; Sweeton et al., 1991; Costa et al., 1994). HNT expression is unaffected by either mutation (Fig. 6J shows an embryo from a cta female; data not shown for fog).

\section{The amnioserosa but not the midgut is required for germ-band retraction}

$h \mathrm{~kb}$ mutants eliminate midgut cell fates and expression of HNT in the presumptive midgut regions at the embryonic termini (Figs 6D, 7C). However $h k b$ mutant embryos undergo normal germ-band extension and retraction (Fig. 7C,D) (Reuter et al., 1993). Thus, neither the midgut per se nor HNT expression in
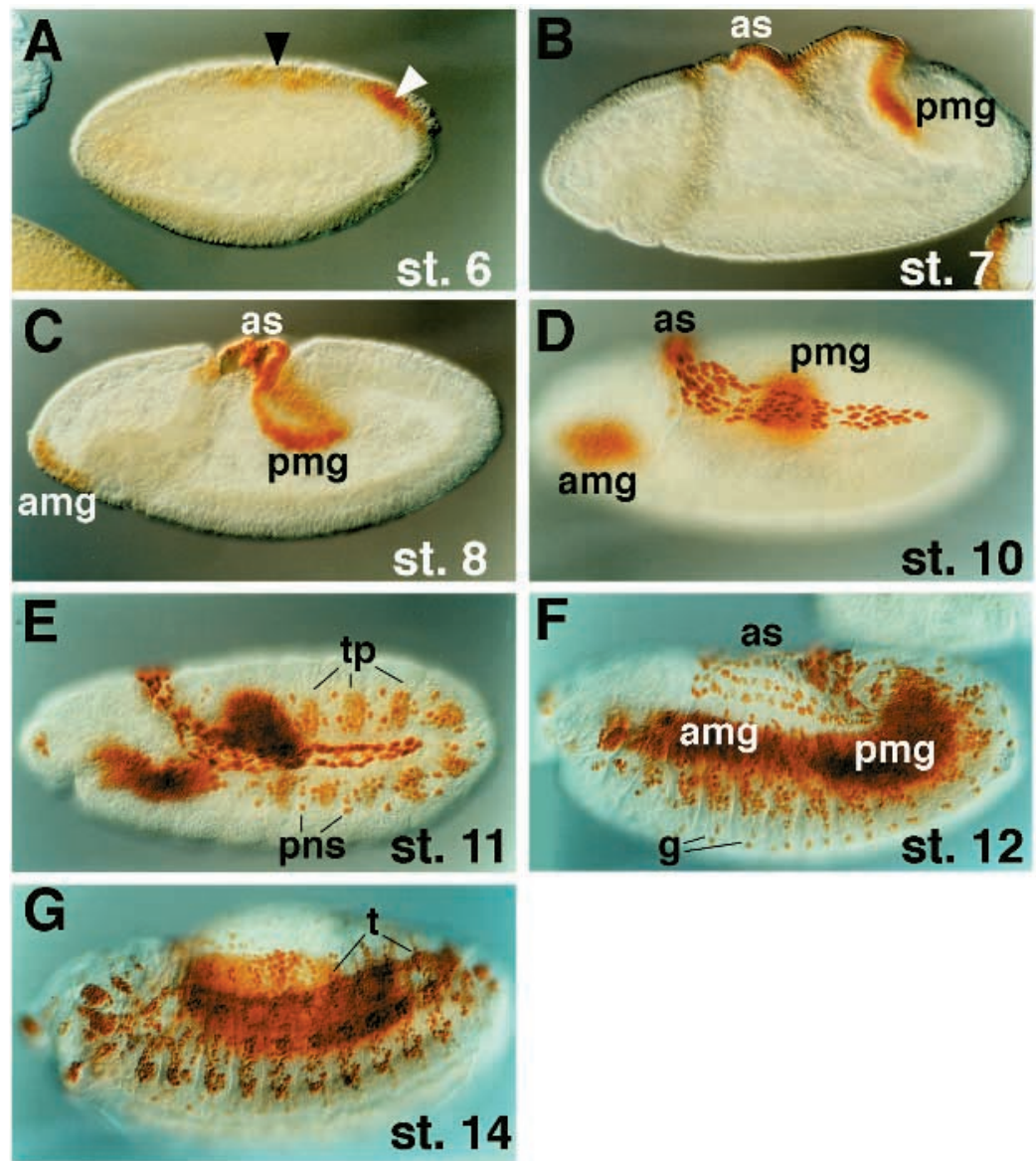

Fig. 5. HNT protein expression. (A) HNT protein starts to accumulate in stage 6 embryos in the posterior midgut primordium (white arrowhead) and dorsally in the presumptive amnioserosa (black arrowhead). (B) In stage 7 embryos, HNT protein can be seen in the posterior midgut (pmg) and amnioserosa (as). (C) At stage 8, HNT protein accumulates in the anterior midgut (amg) primordium as well as the posterior midgut and amnioserosa. (D) A fully germ-band-extended embryo (stage 10) shows HNT protein in the midgut and in the large nuclei of amnioserosal cells. (E) HNT appears in the tracheal pits (tp), peripheral and CNS glial cells (not visible) and peripheral nervous system (pns) as they form in stage 11 embryos. In the embryo shown here, CNS expression has not yet begun. (F) During germ-band retraction, HNT can be seen in the CNS glial cells (g) of stage 12 embryos. (G) A germ-band-retracted embryo (stage 14) shows continued accumulation of HNT in the amnioserosa (out of focal plane), midgut, CNS (out of focal plane), pns and tracheae (t). Embryos are oriented with anterior to the left and dorsal toward the top of the page. 

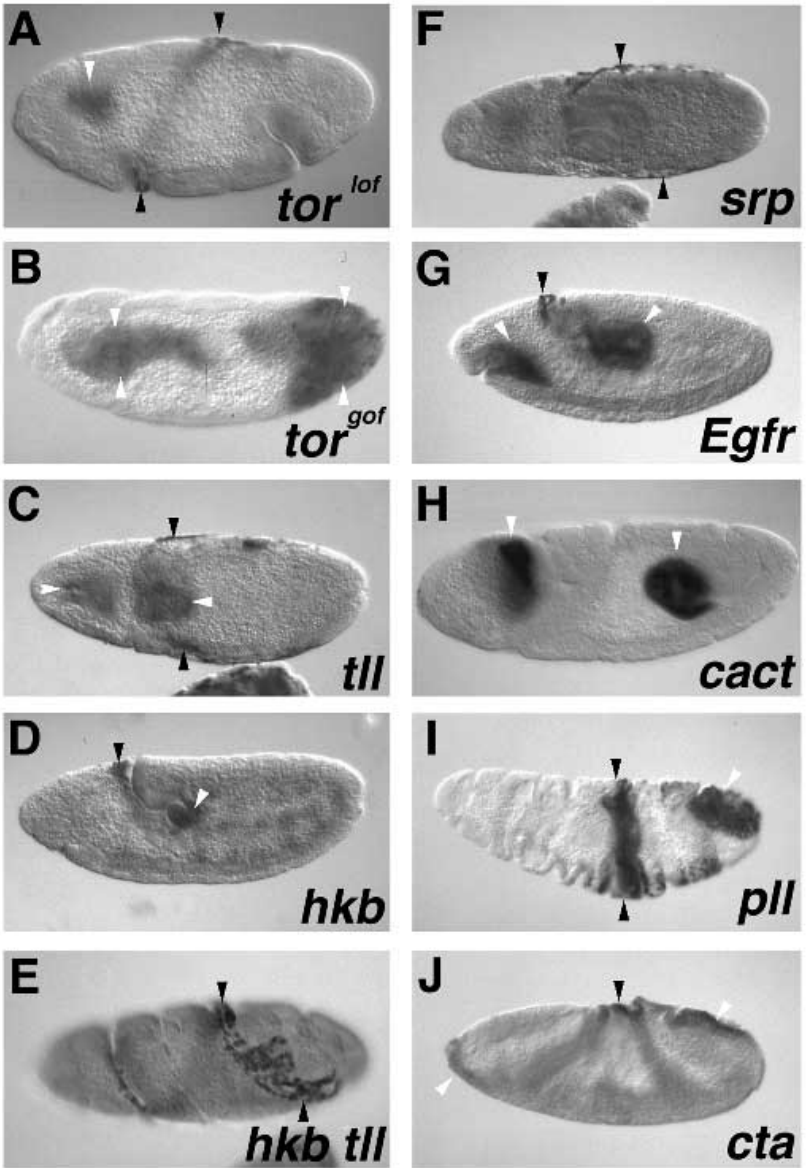

Fig. 6. Regulation of HNT expression. (A) Embryo from a homozygous torso loss-of-function (tor ${ }^{P M 51}$ ) mother lacks HNT in the posterodorsal region while accumulation still occurs in the presumptive amnioserosa dorsally (black arrowheads) and in the anterior midgut rudiment (white arrowhead). The twisted gastrulation phenotype exhibited by tor loss-of-function mutants is apparent. (B) Embryos from homozygous torso ${ }^{\text {splc }}$ gain-of-function mothers lack dorsal HNT accumulation while the enlarged posterior and anterior midgut primordia (white arrowheads) exhibit concomitant expanded HNT accumulation. (C) The HNT accumulation pattern is largely unaffected in a $t l l^{l}$ mutant embryo (amnioserosa, black arrowheads; midgut, white arrowheads). (D) HNT accumulation in the anterior and posterior termini is lost in $h k b^{2}$ mutant embryos (see also Fig. 7A). Posteriorly, only the Malpighian tubule primordium expresses HNT (white arrowhead). Amnioserosal expression is normal (black arrowhead). (E,F) Accumulation of HNT in the regions that normally give rise to endoderm and Malpighian tubules is lost while amnioserosal expression (black arrowheads) is unaffected in $h k b^{2} \mathrm{tll}^{1}$ double mutant embryos (E; gastrulation is twisted in these embryos) and in $s r p^{9 L}$ mutant embryos (F). (G) HNT expression is normal in $E g f r f l$ mutant embryos (amnioserosa, black arrowhead; midgut, white arrowheads). (H) Embryos derived from cactus $^{A 2} /$ cactus $^{H E 9}$ mothers lose dorsal HNT expression while midgut expression remains (white arrowheads). (I) Embryos derived from pelle $e^{078} /$ pelle $^{385}$ mothers have an expanded amnioserosa and thus an expanded dorsal domain of HNT accumulation (black arrowheads), normal expression in the posterior midgut (white arrowhead) and loss of HNT from the region that would normally form the anterior midgut. (J) Embryos from concertina ${ }^{W U 31}$ females have normal HNT expression in the amnioserosa (black arrowhead) and in the midgut (white arrowheads). Embryos are oriented with anterior to the left. Dorsal is toward the top of the page in A, B, D, E, $\mathrm{G}, \mathrm{H}, \mathrm{I}$ and $\mathrm{J}$, while the embryos in $\mathrm{C}$ and $\mathrm{F}$ are viewed from the dorsal side.
Fig. 7. HINDSIGHT expression and germ-band retraction in $h k b$ and $t l d$ single and double mutants. (A,C,E,G) Embryos in which HNT protein was visualized using anti-HNT antibody 27B8 1G9 (see Materials and Methods). (B,D,F,H) Cuticle preparations. (A,B) Wild-type embryos. (C,D) $h k b^{2}$ mutant embryos lack expression of HNT in the terminal domains that would normally form the midgut (C). However, germ-band extension (C) and retraction (D) occur normally. (E,F) $t l d^{9} /$ tld $^{68-62}$ mutant embryos lack dorsal expression of HNT in the region that would normally form the amnioserosa (E) and fail in germ-band extension (E,F; in F A8 is out of the focal plane). (G,H) $h k b^{2} t l d^{9}$ double mutant embryos lack HNT expression in both the termini and the dorsocentral regions $(\mathrm{G})$. They undergo germ-band extension $(\mathrm{G})$ but fail in retraction (H). In all cases, anterior is to the left and dorsal towards the top of the page. See legend to Fig. 5 for abbreviations.
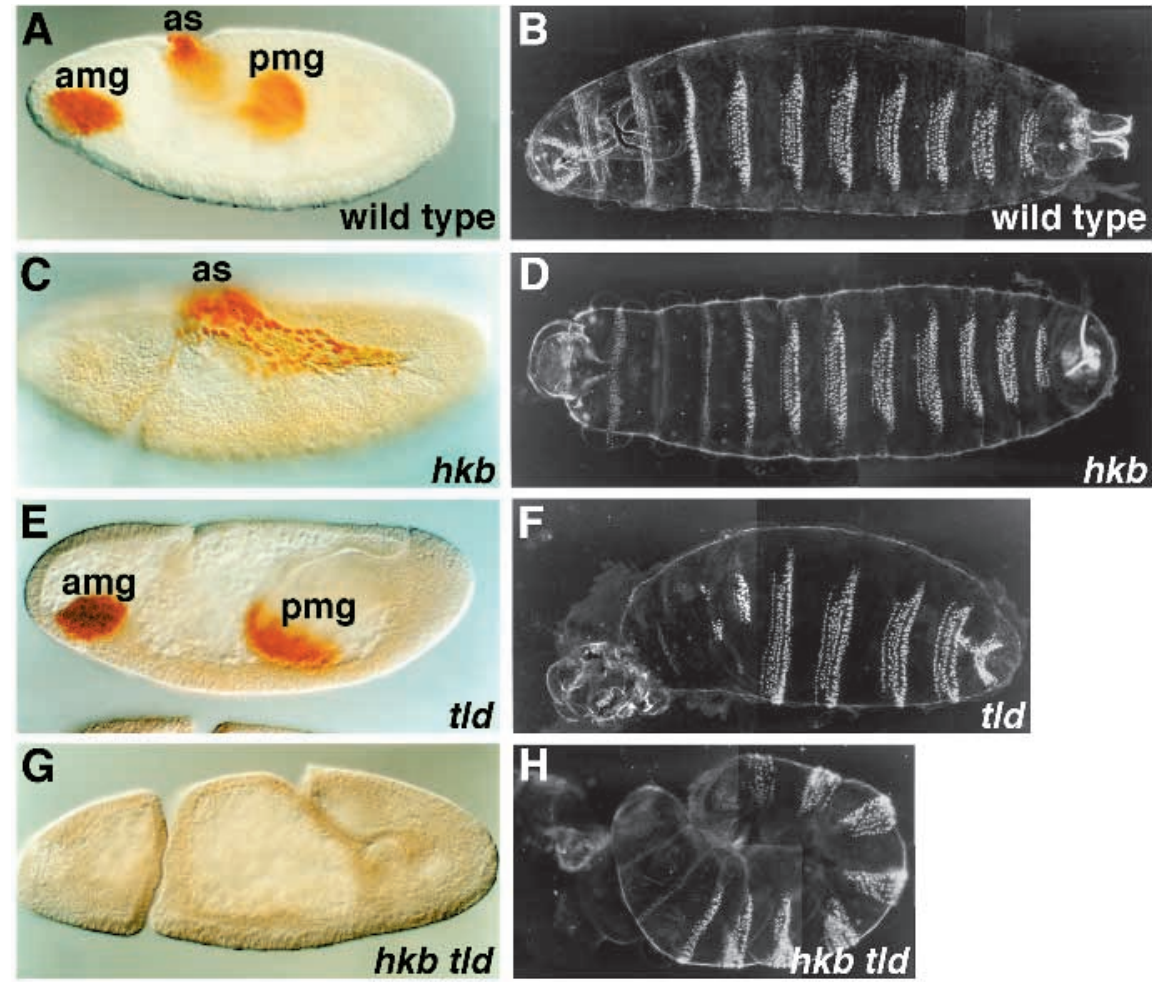

the termini is necessary for germ-band retraction, while dorsal HNT expression in the amnioserosa is sufficient for retraction.
Strongly ventralizing dorsoventral pattern mutants such as zen and tld eliminate amnioserosa cell fates and dorsal 
expression of HNT (Fig. 7E; $t l d^{9} / t l d^{68-62}$ ). However, assaying the function of the amnioserosa and dorsal HNT expression in germ-band retraction is not possible using these mutants because they fail to undergo germ-band extension (Fig. 7E,F).

$h k b^{2} t l d^{9}$ double mutant embryos lack HNT expression dorsally as well as in the termini (Fig. 7G) but undergo germband extension (Fig. 7G,H), thus allowing us to assay germband retraction in the absence of both midgut and amnioserosa. Strikingly, $h k b^{2} t l d^{9}$ double mutant embryos fail to undergo germ-band retraction (Fig. 7H). These results suggest that the amnioserosa per se - and likely HNT expression in this tissue - is necessary for germ-band retraction (see Discussion).

\section{DISCUSSION}

We have shown that hnt gene function is required for germband retraction and that hnt mutations do not cause defects in this morphogenetic process as an indirect consequence of misspecification of cellular positional values or tissue identity. hnt encodes a large zinc-finger protein that accumulates in the nuclei of several tissues prior to germ-band retraction. Strikingly, hnt is not expressed in the epidermal ectoderm, the tissue that undergoes the morphogenetic alterations that drive retraction. Analyses of hnt expression and germ-band retraction in mutants that lack specific tissues in which HNT normally accumulates suggests that hnt expression in the extraembryonic amnioserosa is necessary and sufficient for retraction.

Two lines of evidence support the conclusion that failure of germ-band retraction is a primary effect of $h n t$ mutations. First, hnt mutant embryos undergo normal pattern and tissue specification in the germ band prior to retraction. Second, the temporal and spatial aspects of germ-band extension are indistinguishable in wild-type and in hnt mutant embryos. Thus, there are no detectable defects either in tissue specification or in morphogenesis prior to germ-band retraction. Of eight molecular markers assayed, one - KRÜPPEL - was abnormal in hnt mutants prior to germ-band retraction. KRÜPPEL is absent from many but not all amnioserosal cells by stage 11 (similar observations have been reported by Ray, 1993). Absence of KRÜPPEL at this stage correlates with the recently reported premature apoptosis of the differentiated amnioserosa in hnt mutants (Frank and Rushlow, 1996). The amnioserosal cells of $h n t^{X E 8 I}$ mutant embryos display similar morphology to those of the wild type until apoptosis commences, leading us to suspect that the lack of KRÜPPEL in the amnioserosa of hnt mutants is an indirect consequence of premature apoptosis, rather than that the Krüppel gene is a regulatory target of HNT. The absence of any retraction defects in Krüppel mutants is consistent with this suggestion.

The hnt gene encodes a large protein with fourteen $\mathrm{C}_{2} \mathrm{H}_{2}$ type zinc fingers. This type of zinc finger is found in many transcription factors and has been shown to function as a DNA-binding domain (Pabo and Sauer, 1992). The arrangement of the HNT zinc fingers is unusual in that twelve of the fourteen fingers occur in widely spaced clusters, each of which includes two or three tandemly arranged zinc fingers. Only two of the fourteen zinc fingers - the ninth and twelfth - are unclustered. The fifth zinc finger does not have the second conserved histidine residue and therefore may be nonfunctional. If so, then four clusters of zinc fingers alternate with isolated functional zinc fingers throughout the length of the protein. In addition to the zinc fingers, the HNT protein contains several structural domains commonly found in transcriptional regulators, including multiple glutamine-rich, proline-rich, serine/theronine-rich and acidic/charged domains. Each of these types of domains has been shown to function in trans to mediate protein-protein interactions important for transcriptional control (Courey and Tjian, 1988; Mermod et al., 1989; Ptashne and Gann, 1990; Stringer et al., 1990; Tanaka and Herr, 1990; Dynlacht et al., 1991; Lin and Green, 1991; Lin et al., 1991; Madden et al., 1991; Han and Manley, 1993). These structural motifs, combined with the nuclear localization of HNT protein as revealed by antibody staining, make it highly likely that HNT protein functions as a transcription factor. The fact that the $h n t^{\mathrm{X} 001}$ mutation results in a protein product truncated after the first three zinc fingers but is only a weak allele (Fig. 2D), suggests that partial function can be conferred by the first cluster of three zinc fingers.

The $h s$-hnt transgene rescues the morphogenetic process of germ-band retraction without causing any dominant gain-offunction defects, strongly suggesting that the role of HNT is permissive rather than instructive; that is, that HNT is involved in the spatial and/or temporal coordination of germ-band retraction, rather than in the implementation of the morphogenetic cell shape changes and movements. The fact that HNT is a zinc-finger protein that is expressed in a distinct set of tissues from those that undergo the morphogenetic alterations, is consistent with this possibility.

Expression of hnt in the amnioserosa dorsally versus in the posterior midgut primordium is regulated, respectively, by the dorsoventral and the terminal gene hierarchies, while expression of $h n t$ in the anterior midgut primordium receives input from both of these pathways (Yip and Lipshitz, 1996). hnt is positioned downstream of the genes that specify endodermal (midgut) identity, such as $h k b$. In contrast, mutations in the early morphogenetic control genes cta and fog do not affect $h n t$ expression. This last result suggests that distinct pathways control the early morphogenetic movements that result in internalization of the mesoderm and endoderm (controlled by cta and $f o g$ ) versus the later morphogenetic movements that drive germ-band retraction (controlled by the U-shaped class of genes that includes $h n t$ ).

HNT expression is normal in embryos mutant at any of four other loci required for germ-band retraction: ush, tup, Egfr (this study) and $\operatorname{inr}$ (M. L. L. and H. D. L., unpublished data). Furthermore, the hs-hnt transgene is unable to rescue ush, tup and Egfr mutants under experimental conditions that rescue hnt (M. L. R. Y. and H. D. L., unpublished data). These data are consistent with ush, tup, inr and Egfr residing either downstream of $h n t$ or in a parallel pathway that regulates germ-band retraction. In contrast, endodermal expression of HNT is missing in a fifth mutant that affects germ-band retraction, srp. This last result is consistent with the fact that $s r p$ is required to establish the identity of the endodermal midgut and is expressed in both the anterior and posterior midgut primordia through stage 9 (Reuter, 1994; Rehorn et al., 1996). Not surprisingly, then, HNT expression is absent in srp mutants since the endoderm is absent. The fact that germ-band retraction is normal in $h k b$ mutants that lack midgut but fails in srp mutants in which the midgut is converted into foregut and hindgut, suggests that loss of HNT from presumptive midgut per se does not result in 
failure of germ-band retraction; rather the failure of retraction in srp mutants must have some other cause.

The most striking result of the present studies is the absence of hnt expression in the epidermal ectodermal cells that undergo the morphogenetic alterations that accomplish germband retraction, and the presence of hnt expression in several other tissue types - notably the endoderm and amnioserosa - prior to and during germ-band retraction. The question thus arises as to the role of these tissues in germ-band retraction. Definitive conclusions will require analyses of embryos genetically mosaic for hnt (M. L. L. and H. D. L., unpublished data). However, at this point, several tentative conclusions can be reached on the basis of genetic and phenotypic studies.

The tissue actually responsible for executing germ-band retraction is the epidermal ectoderm. As described in the Introduction, morphological and anatomical analyses of developing embryos show that epidermal ectodermal cells undergo extensive shape changes as well as local rearrangements during germ-band retraction (Martinez Arias, 1993). These processes initiate in the thoracic region and proceed posteriorly, driving germ-band movement around the posterior pole of the embryo (Martinez Arias, 1993). In contrast, the mesoderm is dispensable for germ-band retraction since embryos lacking mesoderm undergo normal germ-band retraction (Leptin et al., 1992). The fact that germ-band retraction is normal in $h k b$ mutants that lack midgut, and thus lack HNT expression in the termini (Fig. 7C,D) suggests that neither the midgut per se nor HNT expression in the termini is essential for germ-band retraction. Further, embryos in which the migration and morphogenesis, but not specification, of the endoderm are disrupted can still undergo germ-band retraction (Reuter et al., 1993; Tepass and Hartenstein, 1994). Thus, neither endodermal nor mesodermal cells per se, nor the migration and morphogenesis of these tissues, are necessary to direct germ-band retraction.

In contrast to the endoderm and mesoderm, a crucial role for the extraembryonic, amnioserosal cells in programming germband retraction is likely. First, since the amnioserosa is present in $h k b$ mutants, which successfully complete germ-band retraction, the amnioserosa is sufficient to program retraction in the absence of midgut. Second, reduction in the size of the amnioserosa (in embryos mutant for weakly ventralizing alleles of zygotically active dorsoventral pattern genes) results in a Ushaped phenotype (Arora and Nüsslein-Volhard, 1992). This suggests that retraction is sensitive to the size of the amnioserosa, consistent with the amnioserosa being necessary for retraction. Third, our double mutant analysis (Fig. 7G,H) confirms that the amnioserosa is necessary for germ-band retraction.

Consistent with an important role for HNT expression in the amnioserosa, and for the amnioserosa per se, it has recently been shown that hnt, srp and ush mutations all result in premature death of the differentiated amnioserosa (Frank and Rushlow, 1996). Indeed, the timing of initiation of the premature germ-band retraction-like movements that we observed in a subset of hnt mutant embryos, correlates well with the stage at which the amnioserosa cells have been reported to undergo premature apoptosis in these mutants (Frank and Rushlow, 1996). Why amnioserosal death should result in premature initiation of this morphogenetic process cannot yet be explained. However, it suggests that the amnioserosa plays both a negative and a positive role in coordinating germ-band retraction: it prevents premature retraction movements while promoting retraction at the appropriate stage of embryogenesis.

Two classes of models - not mutually exclusive - could explain the role of the amnioserosa in germ-band retraction. The first, or 'physical' model, proposes that physical contact between the amnioserosa and the epidermal ectoderm is important for retraction. For example, cell shape changes in the amnioserosa may be necessary to drive, or to allow, retraction. The second, or 'chemical' model, suggests that a (possibly diffusible) signal from the amnioserosa to the epidermal ectoderm directs or coordinates the ectodermal cell shape changes that drive germ-band retraction. These models differ in several respects. Most importantly, the former predicts that the amnioserosa must be present for retraction to occur, while the latter predicts that the amnioserosa per se may be dispensible as long as the appropriate signals to the ectoderm are provided.

Several lines of evidence make us supect that the amnioserosa produces or activates signal(s) that coordinate the morphogenetic alterations in the ectoderm during germ-band retraction. Among the loci required for germ-band retraction, hnt, srp, inr and Egfr are the only four for which information regarding the molecular nature of the gene products and expression patterns is available (this study; Raz and Shilo, 1993; Fernandez et al., 1995; Rehorn et al., 1996). Expression and function of the zinc-finger-containing GATA-like factor, SRP, has been considered above. Both the EGFR (M. L. L. and H.D.L, unpublished data) and the INR (Fernandez et al., 1995) are expressed throughout the embryo with the exception that the INR is never present in the amnioserosa and the EGFR is absent from the amnioserosa after stage 10 (M. L. L. and H. D. L., unpublished data). Based on these expression patterns and the fact that the products of these last two genes are transmembrane receptor tyrosine kinases, it is possible that coordinating signals from the amnioserosa are received in the ectoderm by the INR and/or EGFR and transduced into the shape changes and local cell rearrangements that drive germ-band retraction. The coordinating signal(s) produced by the amnioserosa may be the ligands for these receptor(s). Alternatively they could be an activity or activities that process or activate the ligand(s). Or they could function more indirectly through effects on the extracellular matrix. Future genetic and molecular analyses will focus on specific tests of these models.

Independent of whether the 'physical' or the 'chemical' model is correct, it will be important for future analyses to distinguish alternative mechanisms by which hnt functions in the amnioserosa to program the germ-band retraction process. It is possible that hnt's only function in the amnioserosa is to prevent premature apoptosis (Frank and Rushlow, 1996). In hnt mutants physical contact between the amnioserosa and epidermal ectoderm, or chemical signaling from the amnioserosa to the epidermal ectoderm, would then be disrupted as a secondary effect of loss of the amnioserosa. Alternatively, hnt may play a dual role in the amnioserosa: on the one hand, hnt might function to promote survival of the amnioserosal cells (preventing, for example, premature retraction movements) while, on the other hand, hnt might play a direct role in regulating production or activation of amnioserosa-to-ectoderm signal(s) that coordinate germ-band retraction.

HNT is expressed in several tissues other than the amnioserosa in the developing embryo. These include the midgut, the ureter of the developing Malpighian tubules, the 
developing tracheal system and glial cells in the nervous system (Fig. 5). Taken together with the fact that HNT is likely to be a transcription factor, it is possible that HNT controls additional morphogenetic events during embryonic and postembryonic development by transcriptionally regulating sets of genes that function to coordinate these processes. Future genetic and molecular analyses will address this possibility.

Special thanks to G. Pflugfelder for kindly providing the chromosomal walk in the vicinity of omb that enabled us to clone hnt. Drosophila stocks were provided by the Bloomington Drosophila Stock Center as well as S. Celniker, P. Gergen, A. Hilliker, M. O'Connor, W. Pak, S. Parkhurst, S. Parks, T. Schüpbach and B.-Z. Shilo. Antibodies were kindly provided by S. Beckendorf, S. Benzer, K. Blochlinger, S. Celniker, T. Kaufman, M. Krasnow, Y. Kuo, M. Levine and E. B. Lewis. Thanks to E. Wieschaus for suggesting the $h k b$ tld experiment, S. Ou of the Caltech Monoclonal Antibody Facility for carrying out the hybridoma fusions involved in anti-HNT monoclonal antibody production, K. Zinn and E. B. Lewis for the use of laboratory equipment after the majority of the Lipshitz laboratory moved to Toronto. We thank G. Boulianne, S. Egan, C.c. Hui, R. McInnes and L. Rochwerger for comments on the manuscript. M. L. R. Y. was supported in part by a predoctoral fellowship from the Howard Hughes Medical Institute and M. L. L. by a postdoctoral National Research Service Award from the USPHS (GM16541). This research was supported by research grants to $\mathrm{H}$. D. L. from the American Cancer Society (DB-14) and the National Cancer Institute of Canada (\#7447) with funds from the Canadian Cancer Society.

\section{REFERENCES}

Altschul, S. F., Gish, W., Miller, W., Myers, E. W., and Lipman, D. J. (1990). Basic local alignment search tool. J. Mol. Biol. 215, 403-410.

Arora, K. and Nüsslein-Volhard, C. (1992). Altered mitotic domains reveal fate map changes in Drosophila embryos mutant for zygotic dorsoventral patterning genes. Development 114, 1003-1024.

Ashburner, M. (1989). Drosophila: A Laboratory Manual. Cold Spring Harbor, NY: Cold Spring Harbor Laboratory Press.

Ausubel, F. M., Brent, R., Kingston, R. E., Moore, D. D., Seidman, J. G., Smith, J. A., and Struhl, K. (eds). (1987). Current Protocols in Molecular Biology. ed. K. Janssen. : New York, NY: John Wiley \& Sons, Inc.

Banga, S. S., Bloomquist, B. T., Brodberg, R. K., Pye, Q. N., Larrivee, D. C., Mason, J. M., Boyd, J. B., and Pak, W. L. (1986). Cytogenetic characterization of the $4 \mathrm{BC}$ region on the $\mathrm{X}$ chromosome of Drosophila melanogaster: localization of the mei-9, norpA and omb genes. Chromosoma 93, 341-346.

Bard, J. (ed). (1994). Embryos. London, England: Wolfe Publishing.

Blochlinger, K., Bodmer, R., Jan, L. Y., and Jan, Y. N. (1990). Patterns of expression of cut, a protein required for external sensory organ development in wild-type and cut mutant Drosophila embryos. Genes Dev. 4, 1322-1331.

Brönner, G., Chu-LaGraff, Q., Doe, C. Q., Cohen, B., Weigel, D., Taubert, H., and Jäckle, H. (1994). Sp1/egr-like zinc-finger protein required for endoderm specification and germ-layer formation in Drosophila. Nature 369, 664-668.

Brown, N. H. and Kafatos, F. C. (1988). Functional cDNA libraries from Drosophila embryos. J. Mol. Biol. 203, 425-437.

Campos-Ortega, J. A. and Hartenstein, V. (1985). The embryonic development of Drosophila melanogaster., Berlin: Springer Verlag.

Celniker, S. E., Keelan, D. J., and Lewis, E. B. (1989). The molecular genetics of the bithorax complex of Drosophila: characterization of the products of the Abdominal-B domain. Genes Dev. 3, 1424-1436.

Clifford, R. and Schüpbach, T. (1989). Coordinately and differentially mutable activities of torpedo, the Drosophila melanogaster homolog of vertebrate EGF receptor gene. Genetics 123, 771-787.

Clifford, R. and Schüpbach, T. (1992). The torpedo (DER) receptor tyrosine kinase is required at multiple times during Drosophila embryogenesis. Development 115, 853-872.

Costa, M., Sweeton, D., and Wieschaus, E. (1993). Gastrulation in Drosophila: cellular mechanisms of morphogenetic movements. Pp. 425-
465. In The Development of Drosophila melanogaster. (ed. M. Bate and A. Martinez-Arias). New York: Cold Spring Harbour Laboratory Press.

Costa, M., Wilson, E. T., and Wieschaus, E. (1994). A putative cell signal encoded by folded gastrulation gene coordinates cell shape changes during Drosophila gastrulation. Cell 76, 1075-1089.

Courey, A. J. and Tjian, R. (1988). Analysis of Sp1 in vivo reveals multiple transcriptional domains, including a novel glutamine-rich activation motif. Cell 55, 887-898.

Diederich, R. J., Pattatucci, A. M., and Kaufman, T. C. (1991). Developmental and evolutionary implications of labial, Deformed and engrailed expression in the Drosophila head. Development 113, 273-281.

Ding, D., Parkhurst, S. M., and Lipshitz, H. D. (1993). Different genetic requirements for anterior RNA localization revealed by the distribution of Adducin-like transcripts during Drosophila oogenesis. Proc. Natl. Acad. Sci. USA 90, 2512-2516.

Dynlacht, B. D., Hoey, T., and Tjian, R. (1991). Isolation of coactivators associated with the TATA-binding protein that mediate transcriptional activation. Cell 66, 563-576.

Eberl, D. F. and Hilliker, A. J. (1988). Characterization of X-linked recessive lethal mutations affecting embryonic morphogenesis in Drosophila melanogaster. Genetics 118, 109-120.

Fernandez, R., Tabarini, D., Azpiazu, N., Frasch, M., and Schlessinger, J. (1995). The Drosophila insulin receptor homolog: a gene essential for embryonic development encodes two receptor isoforms with different signaling potential. EMBO J. 14, 3373-3384.

Frank, L. H. and Rushlow, C. (1996). A group of genes required for maintenance of the amnioserosa tissue in Drosophila. Development 122, 1343-1352.

Fujita, S. C., Zipursky, S. L., Benzer, S., Ferrus, A., and Shotwell, S. L. (1982). Monoclonal antibodies against the Drosophila nervous system. Proc. Natl. Acad. Sci USA 79, 7929-7933.

Gaul, U., Seifert, E., Schuh, R., and Jäckle, H. (1987). Analysis of Krüppel protein distribution during early Drosophila development reveals posttranscriptional regulation. Cell 50, 639-647.

Giniger, E., Jan, L. Y., and Jan, Y. N. (1993). Specifying the path of the intersegmental nerve of the Drosophila embryo: a role for Delta and Notch. Development 117, 431-440.

Han, K. and Manley, J. L. (1993). Transcriptional repression by the Drosophila Even-skipped protein: definition of a minimal repression domain. Genes Dev. 7, 491-503.

Harbecke, R. and Lengyel, J. A. (1995). Genes controlling posterior gut development in the Drosophila embryo. Roux's Archiv. Dev. Biol. 204, 308329 .

Harlow, E. and Lane, D. P. (1988). Antibodies: A Laboratory Manual. Cold Spring Harbor, NY: Cold Spring Harbor Laboratory Press.

Irvine, K. D. and Wieschaus, E. (1994). Cell intercalation during Drosophila germband extension and its regulation by pair-rule segmentation genes. Development 120, 827-841.

Jürgens, G., Wieschaus, E., Nüsslein-Volhard, C., and Kluding, H. (1984). Mutations affecting the pattern of the larval cuticle in Drosophila melanogaster. II. Zygotic loci on the third chromosome. Roux's Archiv. Dev. Biol. 193, 283-295.

Kam, Z., Minden, J. S., Agard, D. A., Sedat, J. W., and Leptin, M. (1991). Drosophila gastrulation: analysis of cell shape changes in living embryos by three-dimensional fluorescence microscopy. Development 112, 365-370.

Kania, M. A., Bonner, A. S., Duffy, J. B., and Gergen, J. P. (1990). The Drosophila segmentation gene runt encodes a novel nuclear regulatory protein that is also expressed in the developing nervous system. Genes Dev. 4 , 1701-1713.

Klingler, M., Erdélyi, M., Szabad, J., and Nüsslein-Volhard, C. (1988). Function of torso in determining the terminal anlagen of the Drosophila embryo. Nature 335, 275-277.

Lamka, M. L., Boulet, A. M., and Sakonju, S. (1992). Ectopic expression of UBX and ABD-B proteins during Drosophila embryogenesis: competition, not a functional hierarchy, explains phenotypic suppression. Development 116, 841-854.

Leptin, M., Casal, J., Grunewald, B., and Reuter, R. (1992). Mechanisms of early Drosophila mesoderm formation. Development 118 Supplement, 23-31.

Lewis, E. B. (1996). The bithorax complex: The first fifty years. Pp. 235-260. In Les Prix Nobel (The Nobel Prizes) 1995. (ed. T. Frängsmyr) Stockholm, Sweden: Almqvist \& Wiksell International.

Lin, Y.-S. and Green, M. R. (1991). Mechanism of action of an acidic transcriptional activator in vitro. Cell 64, 971-981.

Lin, Y.-S., Ha, E., Maldonado, E., Reinberg, D., and Green, M. R. (1991). 
Binding of general transcription factor TFIIB to an acidic activating region. Nature 353 ,

Lindsley, D. L. and Zimm, G. G. (1992). The Genome of Drosophila melanogaster. San Diego: Academic Press.

Macdonald, P. M. and Struhl, G. (1986). A molecular gradient in early Drosophila embryos and its role in specifying body pattern. Nature 324, 537545.

Madden, S. L., Cook, D. M., Mooris, J. F., Gashler, A., Sukhatme, V. P., and Rauscher, I., F.J. (1991). Transcriptional repression mediated by the WT1 Wilms Tumor gene product. Science 253, 1550-1553.

Martinez Arias, A. (1993). Development and patterning of the larval epidermis of Drosophila. In The Development of Drosophila melanogaster. (ed. M. Bate and M. Martinez Arias). pp. 517-608. Cold Spring Harbor, NY: Cold Spring Harbor Laboratory Press.

Mermod, N., O'Neill, E. A., Kelly, T. J., and Tjian, R. (1989). The prolinerich transcriptional activator of CTF/NF-1 is distinct from the replication and DNA binding protein. Cell $\mathbf{5 8}, 741-753$

Nüsslein-Volhard, C. (1996). The identification of genes controlling development in flies and fishes.In Les Prix Nobel (The Nobel Prizes) 1995. (ed. T. Frängsmyr). pp. 273-294. Stockholm, Sweden: Almqvist \& Wiksell International.

Nüsslein-Volhard, C., Wieschaus, E., and Kluding, H. (1984). Mutations affecting the pattern of the larval cuticle in Drosophila melanogaster. I. Zygotic loci on the second chromosome. Roux's Archiv. Dev. Biol. 193, 267-282.

Oliver, B., Perrimon, N., and Mahowald, A. P. (1988). Genetic evidence that the sans fille locus is involved in Drosophila sex determination. Genetics 120, 159-171.

Pabo, C. O. and Sauer, R. T. (1992). Transcription factors - structural families and principles of DNA recognition. Ann. Rev. Biochem. 61, 1053-1095.

Parks, S. and Wieschaus, E. (1991). The Drosophila gastrulation gene concertina encodes a $\mathrm{G \alpha}$-like protein. Cell 64, 447-458.

Patel, N. H., Martin-Blanco, E., Coleman, K. G., Poole, S. J., Ellis, M. C., Kornberg, T. B., and Goodman, C. S. (1989). Expression of engrailed Proteins in Arthropods, Annelids, and Chordates. Cell 58, 955-968.

Pflugfelder, G. O., Schwarz, H., Roth, H., Poeck, B., Sigl, A., Kerscher, S., Jonschker, B., Pak, W. L., and Heisenberg, M. (1990). Genetic and molecular characterization of the optomotor-blind gene locus in Drosophila melanogaster. Genetics 125, 91-104.

Pignoni, F., Balderelli, R. M., Steingrímmson, E., Diaz, R. J., Patapoutian, A., Merriam, J. R., and Lengyel, J. A. (1990). The Drosophila gene tailless is expressed at the embryonic termini and is a member of the steroid receptor superfamily. Cell 62, 151-163.

Poole, S. J., Kauvar, L. M., Drees, B., and Kornberg, T. (1985). The engrailed locus of Drosophila: structural analysis of an embryonic transcript. Cell 40, 37-43.

Ptashne, M. and Gann, A. (1990). Activators and targets. Nature 346, 329331.

Ray, R. P. (1993). Dorsal-ventral patterning in the Drosophila embryo. Ph.D Thesis, Harvard University.

Raz, E., Schejter, E. D., and Shilo, B.-Z. (1991). Interallelic complementation among DER/flb alleles: implications for the mechanism of signal transduction by receptor-tyrosine kinases. Genetics 129, 191-201.

Raz, E. and Shilo, B.-Z. (1993). Establishment of ventral cell fates in the Drosophila embryonic ectoderm requires DER, the EGF receptor homolog. Genes Dev. 7, 1937-1948.

Rehorn, K.-P., Thelen, H., Michelson, A. M., and Reuter, R. (1996). A molecular aspect of hematopoesis and endoderm development common to vertebrates and Drosophila. Development 122, 4023-4031.

Reuter, D. and Leptin, M. (1994). Interacting function of snail, twist and huckebein during the early development of germ layers in Drosophila. Development 120, 1137-1150.

Reuter, R. (1994). The gene serpent has homeotic properties and specifies endoderm versus ectoderm within the Drosophila gut. Development 120, 1123-1135.

Reuter, R., Grunewald, B., and Leptin, M. (1993). A role for the mesoderm in endodermal migration and morphogenesis in Drosophila. Development 119, $1135-1145$

Rubin, G. M. and Spradling, A. C. (1982). Transposition of cloned P elements into Drosophila germline chromosomes. Science 218, 341-347.

Sambrook, J., Fritsch, E. F., and Maniatis, T. (1989). Molecular Cloning: A Laboratory Manual. Cold Spring Harbor: Cold Spring Harbor Laboratory Press.

Schüpbach, T. and Wieschaus, E. (1986). Maternal-effect mutations altering the anterior-posterior pattern of the Drosophila embryo. Roux's Archiv. Dev. Biol. 195, 302-317.

Schüpbach, T. and Wieschaus, E. (1989). Female sterile mutations on the second chromosome of Drosophila melanogaster. I. Maternal effect mutations. Genetics 121, 101-117.

Shimell, M. J., Ferguson, E. L., Childs, S. R., and O'Connor, M. B. (1991). The Drosophila dorsal-ventral patterning gene tolloid is related to human bone morphogenetic protein-1. Cell 67, 469-481.

Smith, D. B. and Johnson, K. S. (1988). Single-step purification of polypeptides expressed in Escherichia coli as fusions with glutathione Stransferase. Gene 67, 31-40.

Spradling, A. C. and Rubin, G. M. (1982). Genetic-transformation of Drosophila with transposable element vectors. Science 218, 348-353.

Strecker, T., Kongsuwan, K., Lengyel, J., and Merriam, J. (1986). The zygotic mutant tailless affects the anterior and posterior of the Drosophila embryo. Devl Biol 113, 64-76.

Strecker, T., Merriam, J. R., and Lengyel, J. A. (1988). Graded requirement for the zygotic terminal gene, tailless, in the brain and tail region of the Drosophila embryo. Development 102, 721-734.

Strecker, T. R., Halsell, S. R., Fisher, W. W., and Lipshitz, H. D. (1989). Reciprocal effects of hyper- and hypoactivity mutations in the Drosophila pattern gene torso. Science 243, 1062-1066.

Strecker, T. R. and Lipshitz, H. D. (1990). Functions of the Drosophila terminal genes in establishing embryonic pattern. Pp. 85-94. In Developmental Biology, UCLA Symp. Mol. Cell. Biol, New Series. (ed. E. H. Davidson, J. V. Ruderman, and J. W. Posakony). New York, NY: Wiley-Liss.

Strecker, T. R., Yip, M. L. R., and Lipshitz, H. D. (1991). Zygotic genes that mediate torso receptor tyrosine kinase functions in the Drosophila embryo. Proc. Natl. Acad. Sci. USA 88, 5824-828.

Strecker, T. R., Yip, M. L. R., and Lipshitz, H. D. (1992). Genetic control of cell fate in the termini of the Drosophila embryo. Dev. Biol. 150, 422-426.

Stringer, K. F., Ingles, C. J., and Greenblatt, J. (1990). Direct and selective binding of an acidic transcriptional activation domain to the TATA-box factor TFIID. Nature 345, 783-786.

Sweeton, D., Parks, S., Costa, M., and Wieschaus, E. (1991). Gastrulation in Drosophila: the formation of the ventral furrow and posterior midgut invaginations. Development 112, 775-789.

Tanaka, M. and Herr, W. (1990). Differential transcriptional activation by Oct-1 and Oct-2: interdependent activation domains induce Oct-2 phosphorylation. Cell 60, 375-386.

Tautz, D. and Pfeifle, C. (1989). A non-radioactive in situ hybridization method for the localization of specific RNAs in Drosophila embryos reveals translational control of the segmentation gene hunchback. Chromosoma $\mathbf{9 8}$, 81-85.

Tepass, U. and Hartenstein, V. (1994). Epithelium formation in the Drosophila midgut depends on the interaction of endoderm and mesoderm. Development 120, 579-590.

Thummel, C. S. and Pirrotta, V. (1991). New pCaSpeR P element vectors. Dros. Inf. News. $2,19$.

Weigel, D., Jürgens, G., Klingler, M., and Jäckle, H. (1990). Two gap genes mediate maternal terminal pattern information in Drosophila. Science $\mathbf{2 4 8}$, 495-498.

Wieschaus, E. (1996). From molecular patterns to morphogenesis: The lessons from Drosoophila. In Les Prix Nobel (The Nobel Prizes) 1995. (ed. T. Frängsmyr) pp. 302-314. Stockholm, Sweden: Almqvist \& Wiksell International.

Wieschaus, E. and Noell, E. (1986). Specificity of embryonic lethal mutations in Drosophila analyzed in germ line clones. Roux's Archiv. Dev. Biol. 195, 63-73.

Wieschaus, E., Nüsslein-Volhard, C., and Jürgens, G. (1984). Mutations affecting the pattern of the larval cuticle in Drosophila melanogaster. III. Zygotic loci on the $\mathrm{X}$ chromosome and the fourth chromosome. Roux's Archiv. Dev. Biol. 193, 296-307.

Yip, M. L. R. (1995). Molecular analysis of morphogenesis in Drosophila: Functions of the hindsight locus. Ph.D. Thesis, California Institute of Technology.

Yip, M. L. R. and Lipshitz, H. D. (1996). The terminal gene hierarchy of Drosophila and the genetic control of tissue specification and morphogenesis. Pp. 83-146. In Advances in Developmental Biology, Vol. 4. (ed. P. Wassarman). Connecticut: JAI Press.

Zusman, S. B. and Wieschaus, E. F. (1985). Requirements for zygotic gene activity during gastrulation in Drosophila melanogaster. Dev. Biol. 111, 359371.

(Accepted 25 March 1997) 